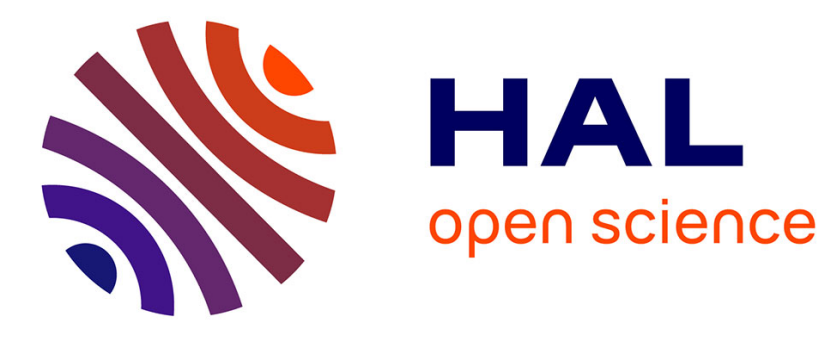

\title{
Non-Interpenetrated Metal-Organic Frameworks Based on Copper(II) Paddlewheel and Oligoparaxylene-Isophthalate Linkers: Synthesis, Structure, and Gas Adsorption
}

Yong Yan, Michal Juríček, François-Xavier Coudert, Nicolaas Vermeulen, Sergio Grunder, Anne Dailly, William Lewis, Alexander. Blake, J. Fraser Stoddart, Martin Schröder

\section{To cite this version:}

Yong Yan, Michal Juríček, François-Xavier Coudert, Nicolaas Vermeulen, Sergio Grunder, et al.. NonInterpenetrated Metal-Organic Frameworks Based on Copper(II) Paddlewheel and OligoparaxyleneIsophthalate Linkers: Synthesis, Structure, and Gas Adsorption. Journal of the American Chemical Society, 2016, 138 (10), pp.3371-3381. 10.1021/jacs.5b12312 . hal-02310199

\author{
HAL Id: hal-02310199 \\ https://hal.science/hal-02310199
}

Submitted on 4 Nov 2019

HAL is a multi-disciplinary open access archive for the deposit and dissemination of scientific research documents, whether they are published or not. The documents may come from teaching and research institutions in France or abroad, or from public or private research centers.
L'archive ouverte pluridisciplinaire HAL, est destinée au dépôt et à la diffusion de documents scientifiques de niveau recherche, publiés ou non, émanant des établissements d'enseignement et de recherche français ou étrangers, des laboratoires publics ou privés. 


\section{Non-Interpenetrated Metal-Organic Frameworks Based on Copper(II) Paddlewheel and Oligoparaxylene-Isophthalate Linkers: Synthesis, Structure, and Gas Adsorption}

Yong Yan,$^{\dagger,+\times}$ Michal Juríček, ${ }^{\S, \|, \times}$ François-Xavier Coudert, ${ }^{\perp}$ Nicolaas A. Vermeulen, ${ }^{\S}$ Sergio Grunder, ${ }^{\S}$ Anne Dailly, ${ }^{\#}$ William Lewis, ${ }^{\dagger}$ Alexander. J. Blake, ${ }^{\dagger}$ J. Fraser Stoddart, ${ }^{*}, \S$ and Martin Schröder*, ${ }^{*}, \dot{\ddagger}$

${ }^{\dagger}$ School of Chemistry, University of Nottingham, University Park, Nottingham NG7 2RD, U.K.

${ }^{\ddagger}$ School of Chemistry, University of Manchester, Oxford Road, Manchester M13 9PL, U.K.

${ }^{\S}$ Center for the Chemistry of Integrated Systems, Department of Chemistry, Northwestern University, 2145 Sheridan Road, Evanston, Illinois 60208, United States

"Department of Chemistry, University of Basel, St. Johanns-Ring 19, 4056 Basel, Switzerland

${ }^{\perp}$ Chimie ParisTech, PSL Research University, CNRS, Institut de Recherche de Chimie Paris, 75005 Paris, France

${ }^{\#}$ Chemical and Environmental Sciences Laboratory, General Motors Corporation, Warren, Michigan 48090, United States

\section{Supporting Information}

ABSTRACT: Two metal-organic framework materials, MFM-130 and MFM-131 (MFM = Manchester Framework Material), have been synthesized using two oligoparaxylene (OPX) tetracarboxylate linkers containing four and five aromatic rings, respectively. Both foftype non-interpenetrated networks contain Kagomé lattice layers comprising $\left[\mathrm{Cu}_{2}(\mathrm{COO})_{4}\right]$ paddlewheel units and isophthalates, which are pillared by the OPX linkers. Desolvated MFM-130, MFM130a, shows permanent porosity (BET surface area of $2173 \mathrm{~m}^{2} / \mathrm{g}$, pore volume of $\left.1.0 \mathrm{~cm}^{3} / \mathrm{g}\right)$, high $\mathrm{H}_{2}$ storage capacity at $77 \mathrm{~K}(5.3$ wt $\%$ at 20 bar and 2.2 wt $\%$ at 1 bar), and a higher $\mathrm{CH}_{4}$ adsorption uptake $\left(163 \mathrm{~cm}^{3}(\mathrm{STP}) / \mathrm{cm}^{3}\right.$ (35 bar and $\left.298 \mathrm{~K}\right)$ ) compared with its structural analogue, NOTT-103. MFM-130a also shows impressive selective adsorption of $\mathrm{C}_{2} \mathrm{H}_{2}, \mathrm{C}_{2} \mathrm{H}_{4}$, and $\mathrm{C}_{2} \mathrm{H}_{6}$ over $\mathrm{CH}_{4}$ at room

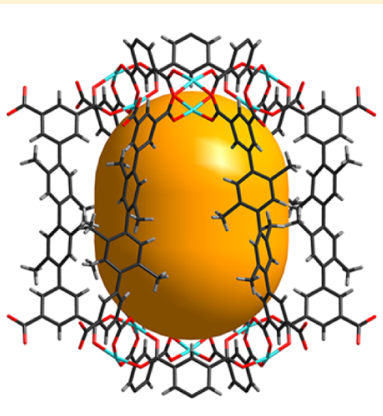

MFM-130

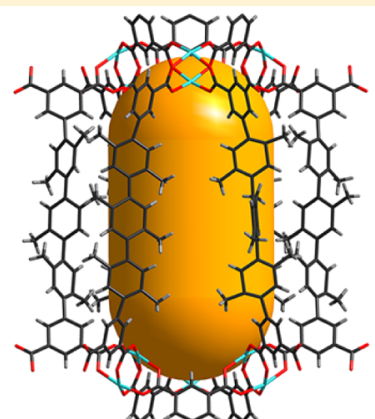

MFM-131 temperature, indicating its potential for separation of $\mathrm{C}_{2}$ hydrocarbons from $\mathrm{CH}_{4}$. The single-crystal structure of MFM-131 confirms that the methyl substituents of the paraxylene units block the windows in the Kagomé lattice layer of the framework, effectively inhibiting network interpenetration in MFM-131. This situation is to be contrasted with that of the doubly interpenetrated oligophenylene analogue, NOTT-104. Calculation of the mechanical properties of these two MOFs confirms and explains the instability of MFM-131 upon desolvation in contrast to the behavior of MFM-130. The incorporation of paraxylene units, therefore, provides an efficient method for preventing network interpenetration as well as accessing new functional materials with modified and selective sorption properties for gas substrates.

\section{INTRODUCTION}

Nanoporous metal-organic frameworks (MOFs) constructed from metal cations or clusters bridged by polyfunctional organic linkers are an important class of hybrid materials which show great promise for gas storage and separation applications. ${ }^{1}$ An advantage of porous MOFs is that their design, structure, and properties can be varied by modification of the organic linkers, which can have different lengths, topologies, and geometries and can incorporate functional groups to enhance preferential binding of guest substrates via optimized pore shapes/diameters for molecular separation. ${ }^{2}$ We have developed a series of framework materials employing linear tetracarboxylate linkers and $\left[\mathrm{Cu}_{2}(\mathrm{COO})_{4}\right]$ paddlewheel units ${ }^{3}$ to generate fof-type networks. ${ }^{4}$ The assembly of isophthalate (benzene-3,5-dicarboxylate) units within tetracarboxylate link- ers with $\left[\mathrm{Cu}_{2}(\mathrm{COO})_{4}\right]$ paddlewheels generates two-dimensional Kagomé lattices, which are pillared by the aromatic backbones of these linkers. Two types of cage structures are formed within this assembly: Cage A, an ellipsoid-shaped cage formed by six linkers and two triangular $\left[\left(\mathrm{Cu}_{2}\right)_{3}\right.$ (isophthalate $\left.)_{3}\right]$ windows at the two ends, with a larger hexagonal $\left[\left(\mathrm{Cu}_{2}\right)_{6}(\text { isophthalate })_{6}\right]$ core structure, and Cage $\mathrm{B}$, a more cylindrical cage formed also by six linkers and two triangular $\left[\left(\mathrm{Cu}_{2}\right)_{3}(\text { isophthalate })_{3}\right]$ windows. These materials show high porosity and high $\mathrm{H}_{2}$ and $\mathrm{CH}_{4}$ storage capacity, with the porosity, storage capacity, and binding energies with $\mathrm{H}_{2}$ and $\mathrm{CH}_{4}$ being tuned by modification of the organic linkers. ${ }^{3}$

Received: November 24, 2015

Published: March 1, 2016 
Elongation of the linear tetracarboxylate units can increase the porosity of the resultant structures, ${ }^{3 \mathrm{~b}}$ but network interpenetration in these fof-systems can occur when the linker is lengthened beyond a certain point. Thus, development of highly porous and non-interpenetrated structures in these systems remains a challenge. ${ }^{5}$ There are several strategies for building non-interpenetrated networks with large organic linkers: (i) building networks with intrinsically non-inter-

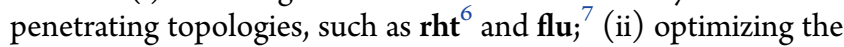
synthesis of MOF materials using different solvents, conditions, and template effects to target preferred non-interpenetrating networks; ${ }^{8}$ and (iii) introducing bulky functional groups in the organic units to create steric hindrance.

Oligoparaxylenes (OPXs) have been developed as efficient building blocks for the construction of MOFs with $\mathrm{Zn}$ (II)/ $\mathrm{Mg}$ (II) nodes. ${ }^{10,11}$ The methyl substituents present in OPXs increase dramatically the solubility of longer oligomers compared to oligophenylene analogues, which become increasingly less soluble with increasing length over just a few aromatic rings. OPX linkers can thus serve as stable, extended, and, most importantly, soluble organic building units or struts. A series of non-interpenetrating MOF-74 analogues have been successfully constructed from 4-carboxylate OPX tectons to give a series of isorecticular $\mathrm{Mg}$ (II) frameworks with pore apertures ranging from 1.4 to $9.8 \mathrm{~nm} .{ }^{11}$ We reasoned that the synthesis of non-interpenetrating fof-type network structures might be achieved using OPX units serving as linear aromatic backbones to connect two isophthalate units to form extended, yet soluble, tetracarboxylate linkers. We envisaged that frameworks with optimized pore size, geometry, and functionality could be accessed by employing such OPX-derived linkers rather than using the more problematic, insoluble oligophenylene units. It is worth noting that methyl substituents present in the OPX struts can not only create hydrophobic pockets, ${ }^{3 e}$ which can aid gas adsorption and separation, but can also impart a degree of steric bulk within pores.

We report herein the synthesis of two new OPX-based linkers, the tetracarboxylates $\mathbf{H}_{4} \mathbf{L}^{\mathbf{I V}}$ and $\mathbf{H}_{4} \mathbf{L}^{\mathrm{V}}$ (Figure 1), incorporating isophthalate moieties, and their coordination to $\left[\mathrm{Cu}_{2}(\mathrm{COO})_{4}\right]$ paddlewheel nodes to form the non-interpenetrated fof-type frameworks MFM-130 and MFM-131. MFM-131 is the first example of a fof-type MOF with ultralong organic struts that does not show network interpenetration. The adsorption of $\mathrm{H}_{2}, \mathrm{CH}_{4}, \mathrm{CO}_{2}$, and small

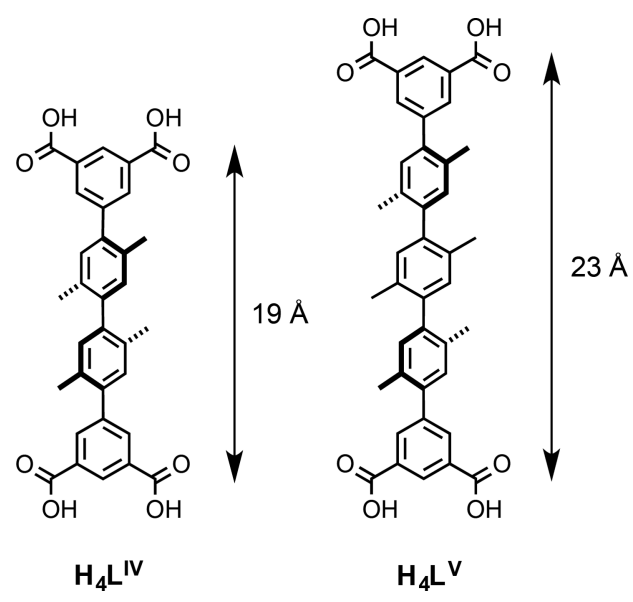

Figure 1. OPX-based tetracarboxylate linkers $\mathrm{H}_{4} \mathrm{~L}^{\mathrm{IV}}$ and $\mathrm{H}_{4} \mathrm{~L}^{\mathrm{V}}$. hydrocarbons in the desolvated form of MFM-130, MFM130a, has been investigated, and the selective adsorption of $\mathrm{CO}_{2}$ over $\mathrm{N}_{2}$, and $\mathrm{C}_{2}$ hydrocarbons (acetylene, ethylene, and ethane) over $\mathrm{CH}_{4}$ in this material is discussed. Desolvation of MFM-131, however, leads to collapse of this material and loss of porosity. Calculation of the mechanical properties of these two MOFs in the elastic regime was, therefore, performed to confirm and explain their distinct properties upon desolvation.

\section{EXPERIMENTAL SECTION}

Materials and Instrumentation. All reagents were purchased from commercial suppliers and used without further purification unless stated otherwise. 4,4'-Diiodo-2,2',5,5'-tetramethyl-1,1'-biphenyl was synthesized as previously reported. ${ }^{12}$ Thin-layer chromatography (TLC) was performed on Merck TLC plates (F254 indicator), and column chromatography carried out on Merck silica gel 60 (Merck grade 9385, 0.040-0.063 mm). Nuclear magnetic resonance (NMR) spectra were recorded on a BrukerAvance III $500 \mathrm{MHz}$ NMR spectrometer at working frequencies of $499.842\left({ }^{1} \mathrm{H}\right)$ and 125.579 $\left({ }^{13} \mathrm{C}\right) \mathrm{MHz}$. The signal corresponding to the residual non-deuterated solvent $\left(\mathrm{CDCl}_{3}: \delta_{\mathrm{H}}=7.26 \mathrm{ppm}\right.$ and $\delta_{\mathrm{C}}=77.16 \mathrm{ppm} ; \mathrm{DMSO}-d_{6}: \delta_{\mathrm{H}}=$ $2.50 \mathrm{ppm}$ and $\delta_{\mathrm{C}}=39.52 \mathrm{ppm} ; \mathrm{PhMe}-\delta_{8}: \delta_{\mathrm{H}}=2.08 \mathrm{ppm}$ and $\delta_{\mathrm{C}}=$ $20.43 \mathrm{ppm}$ ) was used as a reference. Solutions of 1 and $\mathbf{4}$ in PhMe- $d_{8}$ were preheated at $90{ }^{\circ} \mathrm{C}$ for $30 \mathrm{~min}$ before acquiring their ${ }^{1} \mathrm{H}$ and ${ }^{13} \mathrm{C}$ NMR spectra at $25{ }^{\circ} \mathrm{C}$. High-resolution mass spectra (HRMS) were measured on an Agilent 6210 time-of-flight (ToF) LC-MS using an ESI source coupled with Agilent 1100 HPLC stack via direct infusion $(0.6 \mathrm{~mL} / \mathrm{min})$. Fourier-transform infrared (FTIR) spectra were performed on a Nicolet iS5 spectrometer using the attenuated total reflectance (ATR) mode. Elemental analyses were carried out on a CE-440 elemental analyzer, and thermogravimetric analyses (TGA) were performed using a TA SDT-600 thermogravimetric analyzer under a flow of $\mathrm{N}_{2}(20 \mathrm{~mL} / \mathrm{min})$ with a heating rate of $5{ }^{\circ} \mathrm{C} / \mathrm{min}$. Powder X-ray diffraction (PXRD) measurements were carried out at room temperature on a PANalytical X'Pert PRO diffractometer with $\mathrm{Cu} \mathrm{K} \alpha_{1}$ radiation $(\lambda=1.5406 \AA)$ at $40 \mathrm{kV}, 40 \mathrm{~mA}$ with a scan speed of $0.02^{\circ} / \mathrm{s}$ and a step size of $0.005^{\circ}$ in $2 \theta$ (Figures S2 and S3).

Gas Sorption Measurements. $\mathrm{H}_{2}, \mathrm{CO}_{2}$, and $\mathrm{N}_{2}$ isotherms were collected using an IGA gravimetric adsorption apparatus (Hiden) in a clean ultra-high-vacuum system with a diaphragm and turbo pumping system. Approximately $120 \mathrm{mg}$ of solvent-exchanged sample was loaded into the sample basket within the adsorption instrument and then degassed under dynamic vacuum at $110{ }^{\circ} \mathrm{C}$ for $12 \mathrm{~h}$ to obtain the fully desolvated sample. In $\mathrm{H}_{2}$ adsorption experiments, ultra-pure plus grade $\mathrm{H}_{2}$ (99.9995\%, BOC Gases) was purified further using calcium aluminosilicate and activated carbon adsorbents to remove trace amounts of water and other impurities before introduction into the IGA system. Volumetric $\mathrm{CH}_{4}$ sorption measurements were performed over the pressure range $0-70$ bar using an automatically controlled Sievert's apparatus (PCT-Pro 2000 from Hy-Energy LLC). Lowpressure $(<1 \mathrm{bar})$ adsorption measurements for $\mathrm{C}_{2}$ hydrocarbons were performed using an Autosorb 1-MP instrument (Quantachrome Instruments). Ultra-high-purity grade $\mathrm{C}_{2} \mathrm{H}_{2}, \mathrm{C}_{2} \mathrm{H}_{4}$, and $\mathrm{C}_{2} \mathrm{H}_{6}$ were used for adsorption measurements.

The temperature-dependent adsorption data were analyzed using the virial equation: ${ }^{13}$

$$
\ln (n / p)=A_{0}+A_{1} n+A_{2} n^{2}+\ldots
$$

where $p$ is pressure, $n$ is the amount adsorbed, and $A_{0}, A_{1}$, etc. are virial coefficients. The Henry's law constant $\left(K_{\mathrm{H}}\right)$ is equal to $\exp \left(A_{0}\right)$, and the selectivity can be derived from the ratio of the constants $K_{\mathrm{H}}$ for different gases.

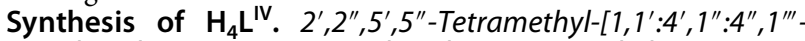
quaterphenyl]-3,3"',5,5"'-tetracarboxylate Tetramethyl Ester (1). A mixture of 5-(4,4,5,5-tetramethyl-1,3,2-dioxaborolan-2-yl)benzene-1,3dicarboxylate dimethyl ester ( $1.66 \mathrm{~g}, 5.17 \mathrm{mmol}), 4,4^{\prime}$-diiodo-2,2',5,5'tetramethyl-1,1'-biphenyl (1.09 g, $2.35 \mathrm{mmol}), \mathrm{PdCl}_{2}(\mathrm{dppf}) \cdot \mathrm{CH}_{2} \mathrm{Cl}_{2}$ $(0.20 \mathrm{~g}, 0.24 \mathrm{mmol}), \mathrm{CsF}(2.14 \mathrm{~g}, 14.1 \mathrm{mmol}), p$-dioxane $(10 \mathrm{~mL})$, 
and $\mathrm{H}_{2} \mathrm{O}(5 \mathrm{~mL})$ was heated at reflux for $18 \mathrm{~h}$ under Ar before $\mathrm{H}_{2} \mathrm{O}$ $(50 \mathrm{~mL})$ was added. The reaction mixture was extracted twice with $\mathrm{CH}_{2} \mathrm{Cl}_{2}$, and the combined organic extracts were washed with brine and dried over $\mathrm{MgSO}_{4}$. After filtration, the solvent was removed by evaporation and the residue purified by column chromatography over silica gel using hexane $/ \mathrm{CH}_{2} \mathrm{Cl}_{2}(1: 1$ to $0: 1)$ as eluent to afford the pure product $(1.16 \mathrm{~g}, 83 \%)$ as a white solid and as a mixture of two enantiomers $(R$ and $S)$, undergoing fast racemization at room temperature. ${ }^{1} \mathrm{H}$ NMR $\left(500 \mathrm{MHz}, \mathrm{PhMe}-d_{8}, \mathrm{ppm}\right): \delta 8.94(\mathrm{t}, J=$ $1.6 \mathrm{~Hz}, 2 \mathrm{H}), 8.41(\mathrm{~d}, J=1.6 \mathrm{~Hz}, 4 \mathrm{H}), 7.11(\mathrm{~s}, 2 \mathrm{H}), 7.04(\mathrm{~s}, 2 \mathrm{H}), 3.52$ $(\mathrm{s}, 12 \mathrm{H}), 2.16(\mathrm{~s}, 6 \mathrm{H}), 2.06(\mathrm{~s}, 6 \mathrm{H}) .{ }^{13} \mathrm{C}$ NMR $\left(125 \mathrm{MHz}, \mathrm{PhMe}-d_{8}\right.$, ppm): $\delta$ (one signal could not be detected because of the signal overlap) $165.8,143.1,141.6,139.3,134.7,133.9,132.7,131.9,131.6$, 131.3, 51.8, 19.9, 19.4. HRMS (ESI): $\mathrm{m} / z$ calcd for $\mathrm{C}_{36} \mathrm{H}_{34} \mathrm{O}_{8}$ : $595.2326\left([M+\mathrm{H}]^{+}\right)$; found 595.2330 .

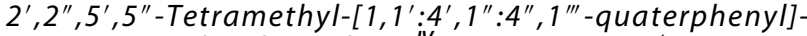
$3,3^{\prime \prime \prime}, 5,5^{\prime \prime \prime}$-tetracarboxylic Acid $\left(\boldsymbol{H}_{4} L^{i v}\right)$. A mixture of $\mathbf{1}(1.12 \mathrm{~g}, 1.88$ $\mathrm{mmol}$ ), aqueous $\mathrm{NaOH}(0.5 \mathrm{M}, 30 \mathrm{~mL})$, and THF $(30 \mathrm{~mL})$ was heated at $50{ }^{\circ} \mathrm{C}$ for $21 \mathrm{~h}$. THF was then removed by evaporation and concentrated $\mathrm{HCl}$ added $(\mathrm{pH} \sim 1)$ to the aqueous residue. The precipitate thus formed was collected by filtration, washed with $\mathrm{H}_{2} \mathrm{O}$, and dried in air to afford the product $(975 \mathrm{mg}, 97 \%)$ as a white solid and as a mixture of two enantiomers ( $R$ and $S$ ), undergoing fast racemization at room temperature. ${ }^{1} \mathrm{H}$ NMR $\left(500 \mathrm{MHz}\right.$, DMSO- $d_{6}$, ppm): $\delta 13.48(\mathrm{br}, 4 \mathrm{H}), 8.48(\mathrm{t}, J=1.6 \mathrm{~Hz}, 2 \mathrm{H}), 8.14(\mathrm{~d}, J=1.5 \mathrm{~Hz}$, $4 \mathrm{H}), 7.25(\mathrm{~s}, 2 \mathrm{H}), 7.11(\mathrm{~s}, 2 \mathrm{H}), 2.24(\mathrm{~s}, 6 \mathrm{H}), 2.09(\mathrm{~s}, 6 \mathrm{H}) .{ }^{13} \mathrm{C} \mathrm{NMR}$ $\left(125 \mathrm{MHz}, \mathrm{DMSO}-d_{6}, \mathrm{ppm}\right): \delta$ 166.6, 141.8, 140.5, 138.3, 133.7, 133.3, 131.9, 131.6, 131.4, 131.0, 128.5, 19.6, 19.1. HRMS (ESI): $\mathrm{m} / z$ calcd for $\mathrm{C}_{32} \mathrm{H}_{26} \mathrm{O}_{8}$ : $537.1555\left([M-\mathrm{H}]^{-}\right)$; found 537.1544 .

Synthesis of $\mathrm{H}_{4} \mathrm{~L}^{\mathrm{V}}$. 4'-Bromo-2', 5'-dimethyl-[1,1'-biphenyl]-3,5dicarboxylate Dimethyl Ester (2). A mixture of 5-(4,4,5,5-tetramethyl1,3,2-dioxaborolan-2-yl)benzene-1,3-dicarboxylate dimethyl ester (3.56 g, $11.1 \mathrm{mmol})$, 1,4-dibromo-2,5-dimethylbenzene (14.6 g, $55.5 \mathrm{mmol})$, $\mathrm{PdCl}_{2}$ (dppf) $\cdot \mathrm{CH}_{2} \mathrm{Cl}_{2}(0.46 \mathrm{~g}, 0.56 \mathrm{mmol}), \mathrm{CsF}$ ( $\left.5.06 \mathrm{~g}, 33.3 \mathrm{mmol}\right), p-$ dioxane $(40 \mathrm{~mL})$, and $\mathrm{H}_{2} \mathrm{O}(20 \mathrm{~mL})$ was heated at reflux under Ar for $18 \mathrm{~h}$ before $\mathrm{H}_{2} \mathrm{O}(100 \mathrm{~mL})$ was added. The reaction mixture was extracted twice with $\mathrm{CH}_{2} \mathrm{Cl}_{2}$, and the combined organic extracts were washed with brine and dried over $\mathrm{MgSO}_{4}$. After filtration, the solvent was removed by evaporation and the residue purified by column chromatography over silica gel using hexane $/ \mathrm{CH}_{2} \mathrm{Cl}_{2}(9: 1$ to $0: 1)$ as eluent to afford the pure product $(5.98 \mathrm{~g}, 71 \%)$ as a white solid. ${ }^{1} \mathrm{H}$ NMR $\left(500 \mathrm{MHz}, \mathrm{CDCl}_{3}, \mathrm{ppm}\right): \delta 8.67(\mathrm{t}, J=1.6 \mathrm{~Hz}, 1 \mathrm{H}), 8.16(\mathrm{~d}, J=$ $1.7 \mathrm{~Hz}, 2 \mathrm{H}), 7.47(\mathrm{~s}, 1 \mathrm{H}), 7.09(\mathrm{~s}, 1 \mathrm{H}), 3.96(\mathrm{~s}, 6 \mathrm{H}), 2.39(\mathrm{~s}, 3 \mathrm{H})$, 2.19 (s, 3H). ${ }^{13} \mathrm{C}$ NMR $\left(125 \mathrm{MHz}, \mathrm{CDCl}_{3}, \mathrm{ppm}\right): \delta 166.3,141.8$, 139.0, 135.6, 134.6, 134.4, 134.1, 132.0, 130.8, 129.5, 124.6, 52.7, 22.4, 19.7. HRMS (ESI): $m / z$ calcd for $\mathrm{C}_{18} \mathrm{H}_{17} \mathrm{BrO}_{4}: 377.0383\left([M+\mathrm{H}]^{+}\right)$; found 377.0392 .

2',5'-Dimethyl-4'-(4,4,5,5-tetramethyl-1,3,2-dioxaborolan-2-yl)[1, 1'-biphenyl]-3,5-dicarboxylate Dimethyl Ester (3). A mixture of 2 $(5.71 \mathrm{~g}, 15.1 \mathrm{mmol})$, bis(pinacolato)diboron $(4.22 \mathrm{~g}, 16.6 \mathrm{mmol})$, $\mathrm{PdCl}_{2}$ (dppf) $\cdot \mathrm{CH}_{2} \mathrm{Cl}_{2}(0.62 \mathrm{~g}, 0.76 \mathrm{mmol}), \mathrm{KOAc}(4.46 \mathrm{~g}, 45.4 \mathrm{mmol})$, and dry DMSO $(60 \mathrm{~mL})$ was heated at $80^{\circ} \mathrm{C}$ under $\mathrm{Ar}$ for $24 \mathrm{~h}$ before $\mathrm{H}_{2} \mathrm{O}(400 \mathrm{~mL})$ was added. The precipitate thus formed was collected by filtration and washed twice with $\mathrm{H}_{2} \mathrm{O}(\sim 1 \mathrm{~L}$ in total $)$ before it was dissolved in $\mathrm{CH}_{2} \mathrm{Cl}_{2}$ and the organic solution dried over $\mathrm{MgSO}_{4}$. After filtration, the solvent was removed by evaporation and the residue purified by column chromatography over silica gel using hexane/ $\mathrm{CH}_{2} \mathrm{Cl}_{2}$ (1:1 to $\left.0: 1\right)$ as eluent to afford the pure product $(5.20 \mathrm{~g}, 87 \%)$ as a white solid. ${ }^{1} \mathrm{H}$ NMR $\left(500 \mathrm{MHz}, \mathrm{CDCl}_{3}, \mathrm{ppm}\right): \delta 8.66(\mathrm{t}, J=1.7$ $\mathrm{Hz}, 1 \mathrm{H}), 8.19$ (d, $J=1.6 \mathrm{~Hz}, 2 \mathrm{H}), 7.69(\mathrm{~s}, 1 \mathrm{H}), 7.05(\mathrm{~s}, 1 \mathrm{H}), 3.96(\mathrm{~s}$, $6 \mathrm{H}), 2.54(\mathrm{~s}, 3 \mathrm{H}), 2.22(\mathrm{~s}, 3 \mathrm{H}), 1.37(\mathrm{~s}, 12 \mathrm{H}) .{ }^{13} \mathrm{C}$ NMR $(125 \mathrm{MHz}$, $\left.\mathrm{CDCl}_{3}, \mathrm{ppm}\right): \delta$ (one signal could not be detected because of the signal overlap) $166.4,142.8,142.7,142.1,138.2,134.4,131.4,131.2$, 130.6, 129.2, 83.6, 52.6, 25.0, 21.8, 19.7. HRMS (ESI): $\mathrm{m} / z$ calcd for $\mathrm{C}_{24} \mathrm{H}_{29} \mathrm{BO}_{6}: 425.2134\left([M+\mathrm{H}]^{+}\right)$; found 425.2140 .

$2^{\prime}, 2^{\prime \prime}, 2^{\prime \prime \prime}, 5^{\prime}, 5^{\prime \prime}, 5^{\prime \prime \prime}-$ Hexamethyl- $\left[1,1^{\prime}: 4^{\prime}, 1^{\prime \prime}: 4^{\prime \prime}, 1^{\prime \prime \prime}: 4^{\prime \prime \prime}, 7^{\prime \prime \prime \prime}\right.$-quinquephenyl]-3,3'"',5,'"'-tetracarboxylate Tetramethyl Ester (4). A mixture of 3 (1.67 g, $4.21 \mathrm{mmol}), 1,4$-diiodo-2,5-dimethylbenzene $(0.726 \mathrm{~g}$, $2.00 \mathrm{mmol}), \mathrm{PdCl}_{2}(\mathrm{dppf}) \cdot \mathrm{CH}_{2} \mathrm{Cl}_{2}(0.16 \mathrm{~g}, 0.20 \mathrm{mmol}), \mathrm{CsF}(1.82 \mathrm{~g}$, $12.0 \mathrm{mmol}), p$-dioxane $(8 \mathrm{~mL})$, and $\mathrm{H}_{2} \mathrm{O}(4 \mathrm{~mL})$ was heated at reflux under $\mathrm{Ar}$ for $38 \mathrm{~h}$ before it was cooled to room temperature. The solid was collected by filtration and washed with $\mathrm{H}_{2} \mathrm{O}$. The solid residue was purified by column chromatography over silica gel using $\mathrm{CH}_{2} \mathrm{Cl}_{2}$, $\mathrm{CH}_{2} \mathrm{Cl}_{2} / \mathrm{PhMe}$ (2:1 to $1: 1$ ), and $\mathrm{PhMe} /$ ethyl acetate (99.5:0.5 to 95:5) as eluents to afford the product $(759 \mathrm{mg}, 54 \%)$ as a white solid and as a $\sim 1: 1$ mixture of two diastereoisomers, a pair of enantiomers $(R R$ and $S S)$ and one meso isomer $(R S)$, undergoing fast isomerization at room temperature. ${ }^{1} \mathrm{H}$ NMR $\left(500 \mathrm{MHz}, \mathrm{PhMe}-d_{8}, \mathrm{ppm}\right): \delta 8.96-$ $8.94(\mathrm{~m}$, two partially overlapped triplets, $J=1.5 \mathrm{~Hz}, 2 \mathrm{H}), 8.42-8.41$ (m, two partially overlapped doublets, $J=1.5 \mathrm{~Hz}, 4 \mathrm{H}), 7.16-7.14(\mathrm{~m}$, two partially overlapped singlets, $2 \mathrm{H}$ ), $7.12-7.10$ (m, two partially overlapped singlets, $2 \mathrm{H}), 7.06-7.03$ (m, two almost resolved singlets ( $\sim 1: 1$ ratio), $2 \mathrm{H}), 3.51$ (m, two overlapped singlets, $12 \mathrm{H}), 2.17-2.15$ (m, two partially overlapped singlets, $6 \mathrm{H}), 2.15-2.12$ (m, two almost resolved singlets $(\sim 1: 1$ ratio), $6 \mathrm{H}), 2.10-2.06$ (m, two resolved singlets $(\sim 1: 1$ ratio), $6 \mathrm{H}) \cdot{ }^{13} \mathrm{C}$ NMR $\left(125 \mathrm{MHz}, \mathrm{PhMe}-d_{8}, \mathrm{ppm}\right): \delta$ (six signals could not be detected because of the signal overlap) 165.83 , 165.82, 143.1, 142.0, 141.9, 140.83, 140.80, 139.22, 139.21, 134.8, 134.0, 133.9, 133.3, 132.7, 132.6, 132.11, 132.06, 131.6, 131.31, $131.25,131.2,129.5,51.80,51.79,19.91,19.90,19.64,19.62,19.44$, 19.42. HRMS (ESI): $m / z$ calcd for $\mathrm{C}_{44} \mathrm{H}_{42} \mathrm{O}_{8}: 699.2952\left([M+\mathrm{H}]^{+}\right)$; found 699.2959 .

$2^{\prime}, 2^{\prime \prime}, 2^{\prime \prime \prime}, 5^{\prime}, 5^{\prime \prime}, 5^{\prime \prime \prime}-$ Hexamethyl- $\left[1,1^{\prime}: 4^{\prime}, 1^{\prime \prime}: 4^{\prime \prime}, 1^{\prime \prime \prime}: 4^{\prime \prime \prime}, 1^{\prime \prime \prime \prime}\right.$-quinque-

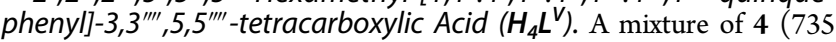
$\mathrm{mg}, 1.05 \mathrm{mmol})$, aqueous $\mathrm{NaOH}(0.5 \mathrm{M}, 30 \mathrm{~mL})$, and THF $(30 \mathrm{~mL})$ was heated at $50{ }^{\circ} \mathrm{C}$ for $42 \mathrm{~h}$. The THF was removed by evaporation and concentrated $\mathrm{HCl}$ added to the aqueous residue to $\mathrm{pH} \sim 1$. The precipitate thus formed was collected by filtration, washed with $\mathrm{H}_{2} \mathrm{O}$, and dried in air to afford the pure product $(705 \mathrm{mg}, 98 \%)$ as a white solid and as a $\sim 1: 1$ mixture of two diastereoisomers, a pair of enantiomers $(R R$ and $S S)$ and one meso isomer $(R S)$, undergoing fast isomerization at room temperature. ${ }^{1} \mathrm{H}$ NMR $\left(500 \mathrm{MHz}\right.$, DMSO- $d_{6}$, $\mathrm{ppm}): \delta 13.40$ (m, two overlapped broad singlets, $4 \mathrm{H}), 8.51-8.46(\mathrm{~m}$, two overlapped triplets, $J=1.7 \mathrm{~Hz}, 2 \mathrm{H}), 8.17-8.12(\mathrm{~m}$, two overlapped doublets, $J=1.7 \mathrm{~Hz}, 4 \mathrm{H}), 7.27-7.06(\mathrm{~m}$, six almost resolved singlets, $6 \mathrm{H}), 2.29-2.20$ (m, two overlapped singlets, $6 \mathrm{H}$ ), $2.13-2.08(\mathrm{~m}$, two overlapped singlets, $6 \mathrm{H}), 2.08-2.03(\mathrm{~m}$, two partially resolved singlets $(\sim 1: 1 \mathrm{ratio}), 6 \mathrm{H}) .{ }^{13} \mathrm{C}$ NMR $(125 \mathrm{MHz}$, DMSO- $\left.d_{6}, \mathrm{ppm}\right): \delta$ (11 signals could not be detected because of the signal overlap) 166.6, 141.9, 140.82, 140.79, 139.6, 138.2, 133.7, $133.27,133.26,132.39,132.38,131.9,131.8,131.5,130.9,130.50$, 130.46, 128.5, 19.54, 19.45, 19.2, 19.1, 18.9. HRMS (ESI): $m / z$ calcd for $\mathrm{C}_{40} \mathrm{H}_{34} \mathrm{O}_{8}$ : 641.2181 $\left([M-\mathrm{H}]^{-}\right)$; found 641.2177.

Synthesis of $\left[\mathrm{Cu}_{2}\left(\mathrm{~L}^{\mathrm{IV}}\right)\left(\mathrm{H}_{2} \mathrm{O}\right)_{2}\right] \cdot 6 \mathrm{DMF} \cdot 3 \mathrm{H}_{2} \mathrm{O}(\mathrm{MFM}-130) \cdot \mathrm{H}_{4} \mathrm{~L}^{\mathrm{IV}}$ $(50 \mathrm{mg}, 0.093 \mathrm{mmol})$ and $\mathrm{Cu}\left(\mathrm{NO}_{3}\right)_{2} \cdot 2.5 \mathrm{H}_{2} \mathrm{O}(0.17 \mathrm{~g}, 0.72 \mathrm{mmol})$ were dissolved in a mixture of $N, N^{\prime}$-dimethylformamide (DMF, 6.0 $\mathrm{mL})$ and $\mathrm{H}_{2} \mathrm{O}(0.5 \mathrm{~mL})$, and the solution was placed in a pressure tube $(15 \mathrm{~mL})$. Upon addition of $6 \mathrm{M} \mathrm{HCl}(15 \mu \mathrm{L})$, the tube was capped and heated at $90{ }^{\circ} \mathrm{C}$ for $16 \mathrm{~h}$, and a large amount of microcrystalline product precipitated. The blue crystals were collected by filtration, washed with warm DMF, and dried in air. Yield: $58.6 \mathrm{mg}$ (80\% based on $\left.\mathbf{H}_{4} \mathbf{L}^{\mathrm{IV}}\right)$. Selected FTIR $\left(\mathrm{cm}^{-1}\right): 3404$ (br, w), 2927 (w), 1657 (vs), 1626 (s), 1588 (m), $1494(\mathrm{~m}), 1435$ (m), 1417 (m), 1367 (vs), 1308 (w), $1284(\mathrm{w}), 1254(\mathrm{~m}), 1187(\mathrm{w}), 1149(\mathrm{w}), 1094$ $(\mathrm{s}), 1062(\mathrm{~m}), 923(\mathrm{w}), 888(\mathrm{w}), 778(\mathrm{~m}), 727(\mathrm{~s}), 701(\mathrm{w}), 686(\mathrm{w})$, 660 (s), $632(w)$. Anal. Calcd (\%) for $\mathrm{C}_{50} \mathrm{H}_{74} \mathrm{Cu}_{2} \mathrm{~N}_{6} \mathrm{O}_{19}$ : C, 50.46; $\mathrm{H}$, 6.27; N, 7.06. Found (\%): C, 50.38; H, 5.75; N, 7.70.

Synthesis of $\left[\mathrm{Cu}_{2}\left(\mathrm{~L}^{\mathrm{V}}\right)\left(\mathrm{H}_{2} \mathrm{O}\right)_{2}\right] \cdot 7 D M F \cdot 4 \mathrm{H}_{2} \mathrm{O}(\mathrm{MFM}-131) \cdot \mathrm{H}_{4} \mathrm{~L}^{\mathrm{V}}$ $(50 \mathrm{mg}, 0.078 \mathrm{mmol})$ and $\mathrm{Cu}\left(\mathrm{NO}_{3}\right)_{2} \cdot 2.5 \mathrm{H}_{2} \mathrm{O}(145 \mathrm{mg}, 0.622$ mmol) were dissolved in a mixture of DMF $(7.0 \mathrm{~mL})$ and $\mathrm{H}_{2} \mathrm{O}(1.0$ $\mathrm{mL})$ in a pressure tube $(15 \mathrm{~mL})$. Upon addition of $6 \mathrm{M} \mathrm{HCl}(20 \mu \mathrm{L})$, the tube was capped and heated in an oil bath at $85{ }^{\circ} \mathrm{C}$ for $48 \mathrm{~h}$ to afford blue crystals. The reaction mixture was allowed to cool to room temperature, and the crystals were washed with warm DMF and dried in air. Yield: $60.9 \mathrm{mg}, 85 \%$ based on $\mathbf{H}_{4} \mathbf{L}^{\mathrm{V}}$. FTIR $\left(\mathrm{cm}^{-1}\right): 3399(\mathrm{br}, \mathrm{w})$, 2924 (w), 1656 (vs), 1625 (s), 1589 (m), 1489 (m), 1435 (w), 1417 (w), 1367 (vs), $1303(\mathrm{w}), 1254(\mathrm{~m}), 1186(\mathrm{w}), 1094(\mathrm{~s}), 1062(\mathrm{~m})$, $955(\mathrm{w}), 887(\mathrm{~m}), 777(\mathrm{~s}), 736(\mathrm{~m}), 724(\mathrm{~s}), 700(\mathrm{w}), 660(\mathrm{~s})$. Anal. Calcd (\%) for $\mathrm{C}_{61} \mathrm{H}_{91} \mathrm{Cu}_{2} \mathrm{~N}_{7} \mathrm{O}_{21}: \mathrm{C}, 52.88 ; \mathrm{H}, 6.62 ; \mathrm{N}, 7.08$. Found (\%): C, 52.48; H, 5.88; N, 7.45. 
X-ray Crystallographic Analyses. Single-crystal diffraction data for MFM-130 were collected at 150(2) K on a Bruker SMART APEX $\mathrm{CCD}$ area detector using graphite-monochromated Mo K $\alpha$ radiation. Data for MFM-131 were collected using synchrotron radiation at Beamline I19 at Diamond Light Source. The details for data collection are included as part of the Crystallographic Information File (CIF) in the Supporting Information. The structures were solved by the direct method and refined by full-matrix least-squares methods on $F^{2}$ using SHELXL-2013. ${ }^{14}$ Hydrogen atoms on the ligands were placed geometrically and refined using a riding model; the hydrogen atoms of the coordinated water molecules could not be located but are included in the formula. DFIX, SADI, and PART instructions were used to deal with the disorder of the paraxylene moieties in the structures. The SQUEEZE option of PLATON ${ }^{15}$ was used to model the contribution of disordered guest molecules to the reflection intensities.

\section{RESULTS AND DISCUSSION}

Single-Crystal X-ray Structures. The tetracarboxylate ligands $\mathbf{H}_{4} \mathbf{L}^{\mathrm{IV}}$ and $\mathbf{H}_{4} \mathbf{L}^{\mathbf{V}}$ (Figure 1) were synthesized by a series of Suzuki cross-coupling reactions (Scheme 1), followed by hydrolysis of the resultant tetraesters. The synthetic procedures and characterization of the target compounds and all their precursors are provided in full detail in the Experimental Section. On the basis of the lengths of these two linear struts (approximately $19 \AA$ for $\mathbf{H}_{4} \mathbf{L}^{\mathrm{IV}}$ and $23 \AA$ for

Scheme 1. Synthesis of $\mathrm{H}_{4} \mathrm{~L}^{\mathrm{IV}}$ and $\mathrm{H}_{4} \mathrm{~L}^{\mathrm{V}}$

(a)<smiles>COC(=O)c1cc([Pb]c2ccccc2)cc(C(=O)OC)c1</smiles><smiles>Cc1cc(-c2cc(I)c(I)cc2C)ccc1I</smiles>

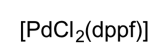

$\mathrm{CsF}$

$p$-Dioxane / $\mathrm{H}_{2} \mathrm{O}$

$83 \%$

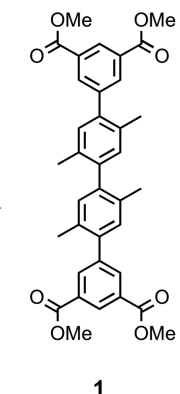

(b)<smiles>COC(=O)c1cc([Pb])cc(C(=O)OC)c1</smiles>

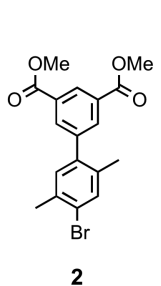

2

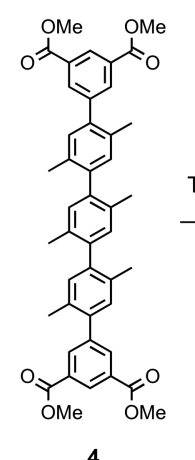

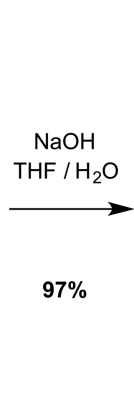
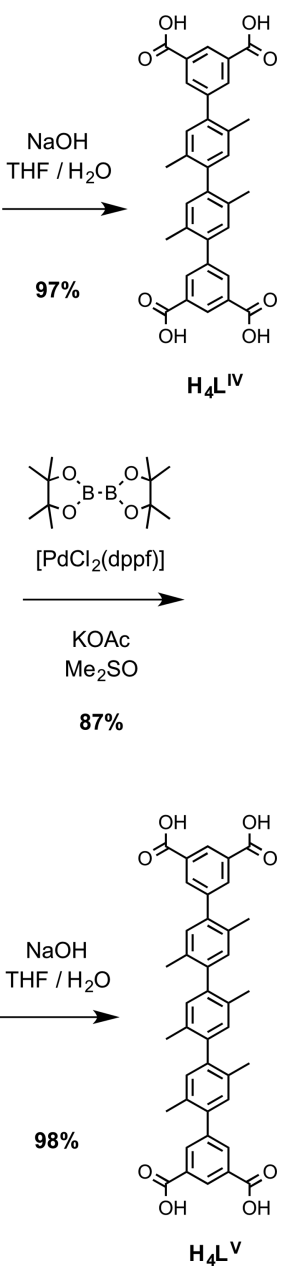

$\mathrm{H}_{4} \mathrm{~L}^{\mathrm{V}}$ ), it was anticipated that nanosized porous structures can be assembled.

Solvothermal reactions of $\mathrm{H}_{4} \mathrm{~L}^{\mathrm{IV}}$ and $\mathrm{H}_{4} \mathrm{~L}^{\mathrm{V}}$ with $\mathrm{Cu}\left(\mathrm{NO}_{3}\right)_{2}$. $2.5 \mathrm{H}_{2} \mathrm{O}$ in a mixture of DMF and $\mathrm{H}_{2} \mathrm{O}$ at $80{ }^{\circ} \mathrm{C}$ for $16 \mathrm{~h}$ afforded blue highly crystalline solids of $\left[\mathrm{Cu}_{2}\left(\mathrm{~L}^{\mathrm{IV}}\right)\left(\mathrm{H}_{2} \mathrm{O}\right)_{2}\right]$. 6DMF-3 $\mathrm{H}_{2} \mathrm{O}$ (MFM-130) and $\left[\mathrm{Cu}_{2}\left(\mathbf{L}^{\mathbf{V}}\right)\left(\mathrm{H}_{2} \mathrm{O}\right)_{2}\right] \cdot 7 \mathrm{DMF}$. $4 \mathrm{H}_{2} \mathrm{O}$ (MFM-131), respectively. The formulae of these two compounds were confirmed by elemental analysis, single-crystal $\mathrm{X}$-ray structure determinations, and TGA (Figure S1). The phase purity of the two bulk crystalline solids was confirmed by PXRD and Le Bail analyses (Figures S2-S4). Single-crystal Xray structure analysis revealed that both MFM-130 and MFM131 crystallize in the trigonal space group $R \overline{3}$. Both rhombohedral lattices in MFM-130 and MFM-131 have similar $a$-axes due to the same type of Kagomé lattice formed by the two-connected isophthalate units with four-connected $\left[\mathrm{Cu}_{2}(\mathrm{COO})_{4}\right]$ paddlewheels. In MFM-130 (Figure 2), because of the steric hindrance caused by methyl substituents, the twoconnected paraxylene units in $\left(\mathrm{L}^{\mathrm{IV}}\right)^{4-}$ are almost perpendicular to each other. The methyl group of the paraxylene unit adjacent to the isophthalate ring forces these two rings to be noncoplanar with a torsion angle of approximately $51^{\circ}$. Thus, the geometrical conformation of the central pair of paraxylene units lock the two terminal isophthalate moieties within the same plane, making the linker $\left(\mathrm{L}^{\mathrm{IV}}\right)^{4-}$ a planar four-connected node when bound to $\left[\mathrm{Cu}_{2}(\mathrm{COO})_{4}\right]$ paddlewheels. MFM-130 has an fof-type network topology constructed by the packing of two types of cages (A and B), and is isostructural with the analogous NOTT-102 constructed from tetracarboxylate linkers containing phenylene instead of paraxylene units. ${ }^{3 b}$ With the methyl groups projecting into the pores, both Cage $\mathrm{A}$ and Cage B in MFM-130 have reduced accessible voids compared to those of the non-functionalized analogue NOTT-102. Cage A has a slim ellipsoid shape with a length of $33 \AA$, a narrow diameter of $7 \AA$ at the two ends and a larger diameter of $18 \AA \AA$ in the center, while Cage $B$ has a thicker cylindrical shape with diameter of $13 \AA$ and length of $16 \AA$ (Figure 2).

MFM-131 has the same fof topology as MFM-130 with the Kagomé nets pillared by three consecutive paraxylene units from $\left(\mathbf{L}^{\mathbf{V}}\right)^{4-}$ (Figure 3). Significantly, MFM-131 is noninterpenetrating despite the extra-long strut $\left(\mathbf{L}^{\mathrm{V}}\right)^{4-}$ used, and this is a rare example of a fof framework with large internal voids (63\%). Cage A in MFM-131 is significantly elongated to $42 \AA$ in length compared to MFM-130 (33 $\AA$ ) due to the presence of an additional paraxylene unit in the tetracarboxylate strut. With a dense population of methyl groups on the walls of the cage, the diameters of the two ends of the ellipsoid are narrowed to $5 \AA$ compared to the oligophenylene analogue NOTT-104. Cage B in MFM-131 is an elongated nanosized cylinder of $13 \AA \times 20 \AA(13 \AA \times 16 \AA$ for MFM-130). The structural analogue NOTT-104 ${ }^{3 \mathrm{~b}}$ constructed from a linear tetracarboxylate linker incorporates the same length of strut used in MFM-131, but without the methyl groups. In this case, two identical fof-type lattices interpenetrate to form a doubly interpenetrated network in NOTT-104 (Figure 3c). The $[\mathrm{Cu} \text { (isophthalate) }]_{n}$ Kagomé lattice in NOTT-104 has two types of windows: a smaller triangular window $\left[\left(\mathrm{Cu}_{2}\right)_{3}\right.$ (isophthalate $\left.)_{3}\right]$ of $6 \AA$ in diameter and a larger hexagonal window $\left.\left[\left(\mathrm{Cu}_{2}\right)_{6} \text { (isophthalate }\right)_{6}\right]$ with an opening of $18 \AA$. Therefore, the narrow end of the ellipsoidal cage from one framework can cross through the wider central opening of a second network, thus allowing network interpenetration in NOTT-104. The $\pi-\pi$ interaction between the phenylene units from two 


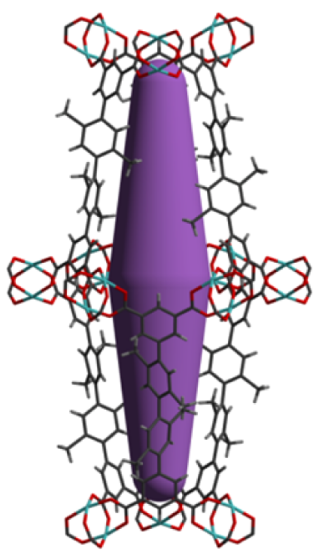

(a)

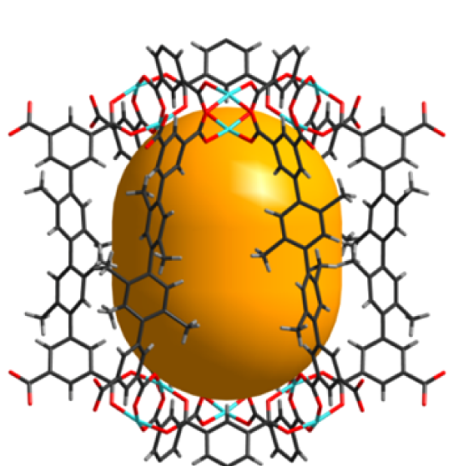

(b)

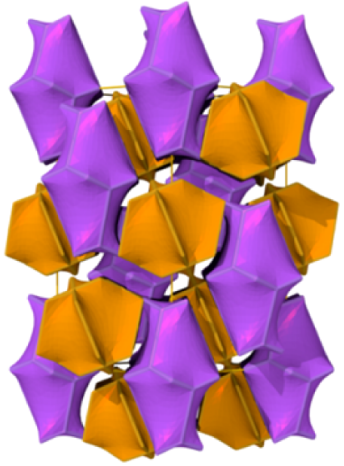

(c)

Figure 2. Views of the single-crystal X-ray structure of MFM-130 comprising two types of cages: (a) an ellipsoid-shaped cage A of length $33 \AA$, comprising six $\left(\mathrm{L}^{\mathrm{IV}}\right)^{4-}$ units and $12\left[\mathrm{Cu}_{2}(\mathrm{COO})_{4}\right]$ paddlewheels, and $(\mathrm{b})$ a cylindrical cage $\mathrm{B}(13 \AA \times 16 \AA)$, formed by 12 linkers and six $\left[\mathrm{Cu}_{2}(\mathrm{COO})_{4}\right]$ paddlewheels. (c) View of fof-type network and the natural tiling of the two types of cages in the framework.

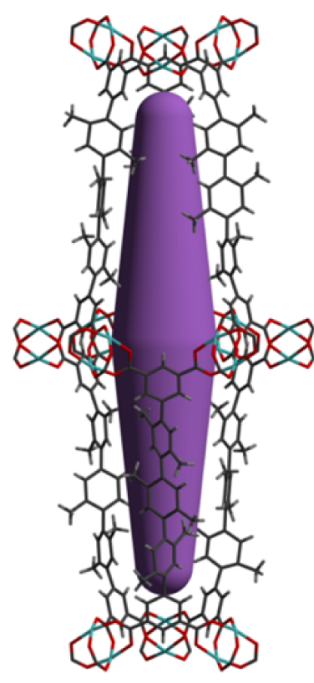

(a)

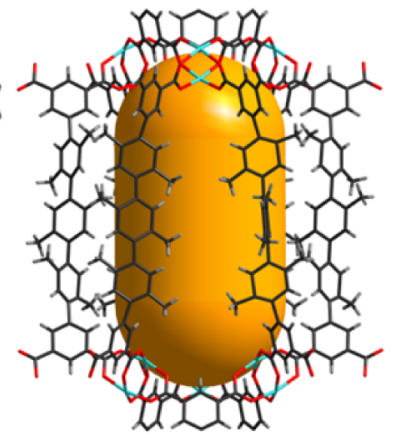

(b)

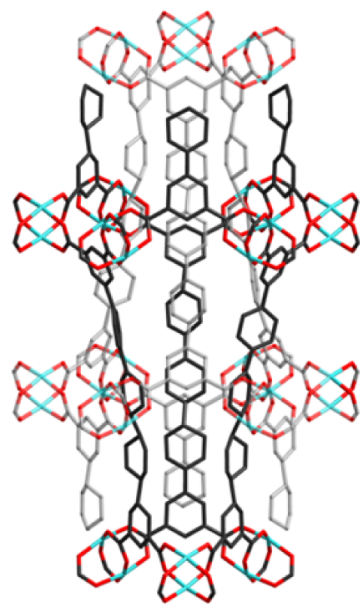

(c)

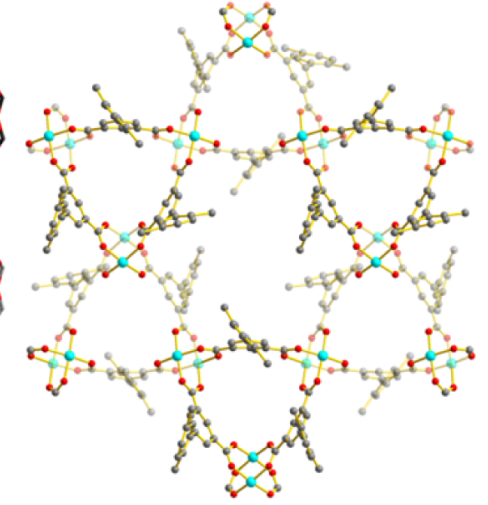

(d)

Figure 3. Views of the single-crystal X-ray structure of non-interpenetrated MFM-131: (a) Cage A, $42 \AA$ in length, and (b) Cage B, with dimensions of $13 \AA \times 20 \AA$. . (c) View of the interpenetrating network in NOTT-104. (d) View of the triangular window in the Kagomé lattice in the MFM-131 framework. The paraxylene rings adjacent to the triangular windows block the space and do not allow the two independent networks to interpenetrate.

different networks further facilitates and stabilizes the network interpenetration. In MFM-131, the opening of the hexagonal window in the Kagomé lattice is significantly smaller because of the presence of six paraxylene units around the window and $\pi-\pi$ interactions between the paraxylene units are inhibited, thus successfully preventing interpenetration of the two fof lattices.

Stabilities of MFM-130 and MFM-131 and Mechanical Property Calculations. The activation of as-synthesized MFM-130 and MFM-131 was investigated for subsequent gas adsorption studies. Both materials were exchanged with acetone for $24 \mathrm{~h}$ before being dried under vacuum at $110^{\circ} \mathrm{C}$ to afford the desolvated samples MFM-130a and MFM-131a, respectively. MFM-130a maintained crystallinity after thermal treatment under vacuum as confirmed by the PXRD analysis (Figure S2). However, after the desolvation process (using both thermal treatment and supercritical $\mathrm{CO}_{2}$ drying) MFM-131 showed almost complete loss of crystallinity, indicating an inherent instability upon desolvation. In order to understand and rationalize the reasons behind the distinct behaviors of MFM-130 and MFM-131 upon desolvation, we calculated the mechanical properties of both structures in the elastic regime (see Supporting Information). ${ }^{16,17}$ The second-order elastic stiffness tensors are shown in Figures S7 and S8, and a summary of their average and directional elastic properties is presented in Table 1. It can be observed that both structures have relatively similar mechanical features (due to their isostructural nature), including a marked anisotropy with stiffer directions (as defined by high Young's modulus) along or near the $c$ axis which is, on average, the principal axis of the organic linkers. Surprisingly, both structures display remarkable negative linear compressibility along the $c$ axis $\left(-59.9 \mathrm{TPa}^{-1}\right.$ for MFM-130 and $-67.6 \mathrm{TPa}^{-1}$ for MFM-131), which we attribute to a hinging mechanism in the fof topology. ${ }^{18}$ This suggests that testing of MFM-130, MFM-131, and other MOFs 
Table 1. Summary of the Mechanical Properties of the Structural Models of MFM-130 and MFM-131 in the Elastic Regime

\begin{tabular}{lcc}
\multicolumn{1}{c}{ elastic property } & MFM-130 & MFM-131 \\
bulk modulus (Hill average) (GPa) & 11.41 & 8.77 \\
Young's modulus (Hill average) (GPa) & 7.79 & 4.69 \\
shear modulus (Hill average) (GPa) & 2.81 & 1.66 \\
minimal Young's modulus (GPa) & 4.43 & 1.42 \\
maximal Young's modulus (GPa) & 11.25 & 12.84 \\
minimal shear modulus (GPa) & 1.73 & 0.48 \\
maximal shear modulus (GPa) & 4.25 & 2.52 \\
largest negative linear compressibility $\left(\mathrm{TPa}^{-1}\right)$ & -59.9 & -67.6 \\
largest positive linear compressibility $\left(\mathrm{TPa}^{-1}\right)$ & 96.7 & 136.9 \\
\hline
\end{tabular}

of fof topology under pressure may generate unusual dynamic effects.

The main difference in the mechanical properties of MFM130 and MFM-131 turns out to be the value of their lowest elastic modulus: the shear modulus (Figure 4). While MFM131 shows lower average Young's and shear moduli than MFM130, MFM-131 shows an especially low directional shear modulus of $0.48 \mathrm{GPa}$ compared to $1.73 \mathrm{GPa}$ for MFM-130. This difference is linked to the lower density and higher porosity of MFM-131 and not to any change in mechanism since both minimal shear moduli correspond to the same direction. The very low shear modulus of MFM-131 is, to our knowledge, the lowest ever calculated for a non-flexible MOF. It explains the low resistance of MFM-131 to solvent evacuation, during which shear forces develop inside the crystal and which can, if they exceed the shear modulus in a specific direction, lead to mechanical instability and trigger a structural transition or collapse. This behavior is similar to the instability shown by some experimentally synthesized ZIF structures upon removal of solvents and guest molecules, ${ }^{19}$ suggesting that a gentler method of desolvation needs to be developed for the highly porous MFM-131 to remain structurally intact upon activation. However, with its densely functionalized methyl groups and large pore structure, MFM-131 may find other applications such as sensing and catalysis where desolvation is not required for the process. The above calculation represents a unique example of how computational simulation of the mechanical properties of MOFs, in this case, a fof-type system consisting of layered Kagomé lattices pillared by OPX units of different lengths, can help rationalize and explain the experimental results. This also improves our understanding of the mechanochemical properties of MOFs, especially those with large pore structures comprising large organic units.

Porosity of MFM-130a. The total accessible volume in MFM-130a after removal of guest solvates and coordinated water molecules is $60 \%$ as determined by the PLATON/VOID routine, ${ }^{15}$ and the desolvated framework has a calculated density of $0.642 \mathrm{~g} / \mathrm{cm}^{3}$, which is more dense than NOTT-102a $\left(0.587 \mathrm{~g} / \mathrm{cm}^{3}\right)$ reflecting the presence of methyl functionalities in the former. The $\mathrm{N}_{2}$ isotherm for MFM-130a at $77 \mathrm{~K}$ shows typical Type I characteristics, indicative of the microporous nature of MFM-130a (Figure 5). The BET surface area is 2173

\section{MFM-130}

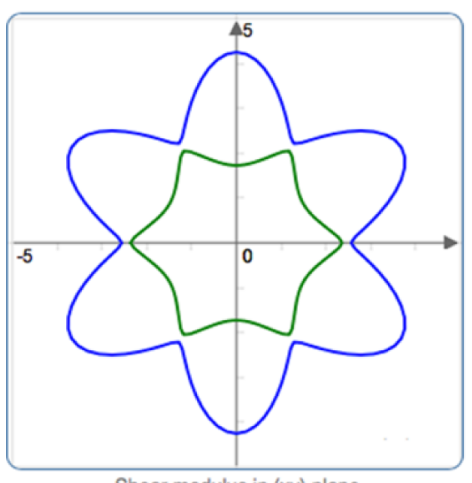

Shear modulus in (xy) plane

MFM-131

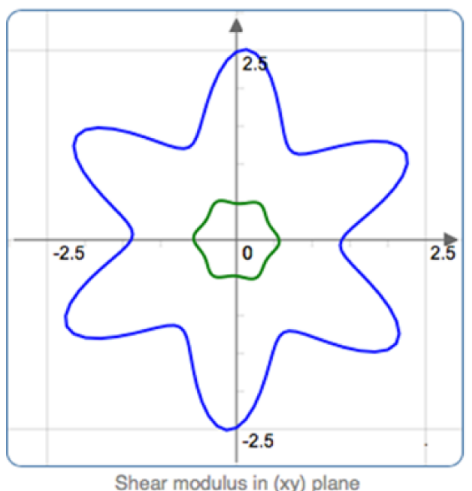

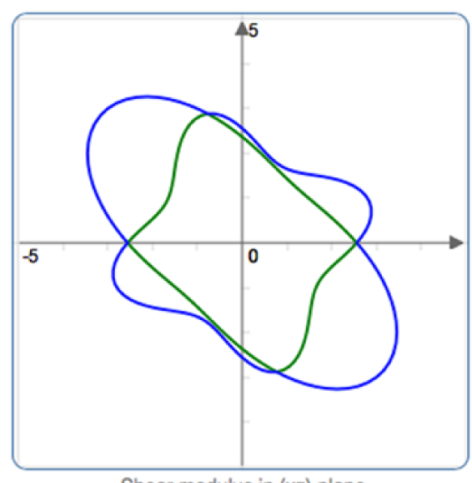

Shear modulus in $(x z)$ plane

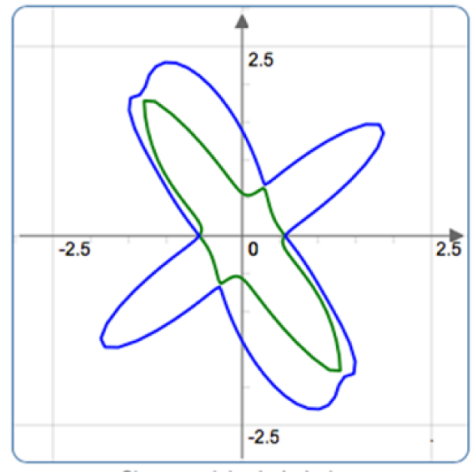

Shear modulus in $(x z)$ plane

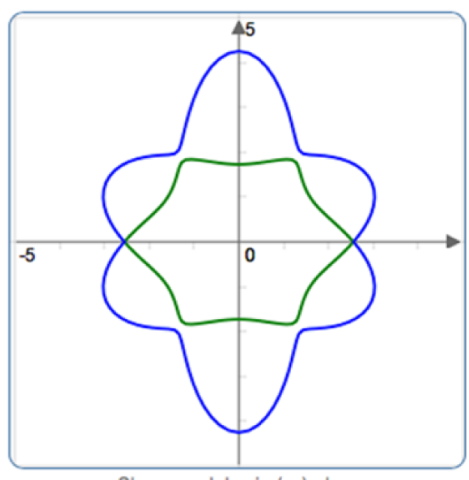

Shear modulus in (yz) plane

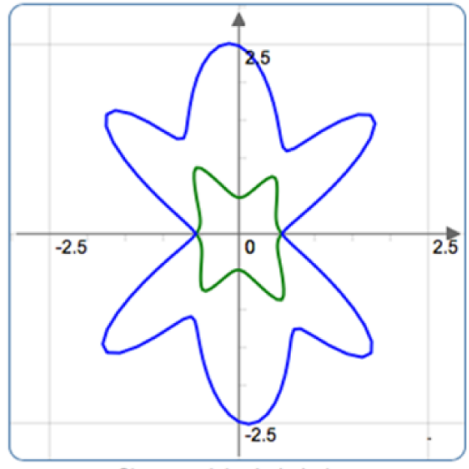

Shear modulus in (yz) plane

Figure 4. Directional shear modulus of MFM-130 and MFM-131 in the ( $x y)$, ( $x z)$, and $(y z)$ planes. Minimal and maximal values of shear modulus for each direction are plotted in green and blue, respectively. 


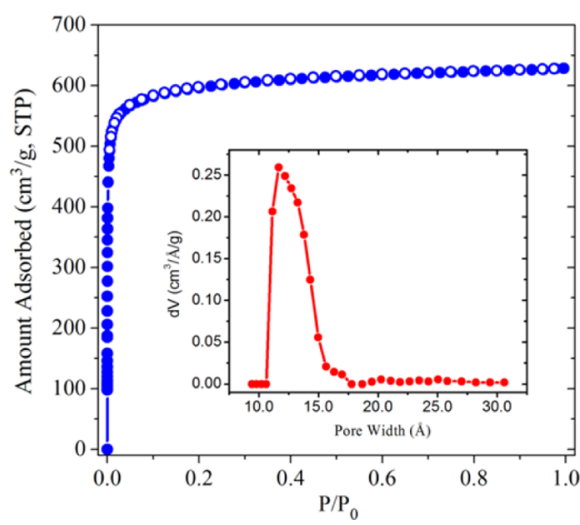

Figure 5. $\mathrm{N}_{2}$ isotherm for MFM-130a at $77 \mathrm{~K}$. The inset shows the pore size distribution, indicating that the pore diameters are distributed between 11 and $15 \AA$ according to the NLDFT model.

$\mathrm{m}^{2} / \mathrm{g}$ and total pore volume is $1.0 \mathrm{~cm}^{3} / \mathrm{g}$ derived from the $\mathrm{N}_{2}$ isotherm. Due to the multiple methyl substituents occupying additional space, MFM-130a shows both a lower BET surface area and total pore volume than the isostructural frameworks NOTT-102, ${ }^{3 \mathrm{~b}}$ NOTT-110, ${ }^{3 \mathrm{C}}$ and NOTT-111 $1^{3 \mathrm{C}}$ containing biphenyl, phenanthrene, and hydrophenanthrene subunits, respectively, in the backbones of the tetracarboxylate linkers. The pore diameters in MFM-130a based on the nonlocal density functional theory (NLDFT) model are narrowly distributed between 11 and $15 \AA$.

$\mathrm{H}_{2}, \mathrm{CH}_{4}$, and $\mathrm{CO}_{2}$ Sorption Properties of MFM-130a. $\mathrm{Cu}$ (II)-based MOFs have been intensively investigated for their $\mathrm{H}_{2}$ storage properties because of their high surface area and the availability of open $\mathrm{Cu}$ (II) sites for providing strong $\mathrm{H}_{2}$ binding sites. ${ }^{20,21}$ Gravimetric $\mathrm{H}_{2}$ sorption isotherms for MFM-130a were collected at 77 and $88 \mathrm{~K}$ up to $20 \mathrm{bar}$ (Figure 6). MFM130a has a lower surface area compared to non-functionalized NOTT-102 leading to a lower $\mathrm{H}_{2}$ adsorption capacity of 5.3 wt\% at 20 bar and $77 \mathrm{~K}$ (6.07 wt\% for NOTT-102), consistent with the physical sorption nature of these materials. MFM-130a can adsorb 2.2 wt $\%$ of $\mathrm{H}_{2}$ at $77 \mathrm{~K}$ and 1 bar, higher than most other MOFs without open metal sites. ${ }^{1 e, 22}$ The isosteric heat of adsorption for $\mathrm{H}_{2}$ in MFM-130a was calculated to be $6.6 \mathrm{~kJ} /$ $\mathrm{mol}$ at zero coverage using the virial method, higher than those for NOTT-102a, NOTT-110a and NOTT-111a, confirming that the methyl groups in MFM-130a can increase the overlapping potential for $\mathrm{H}_{2}$ molecules.

$\mathrm{CH}_{4}$ storage has been widely studied due to the importance of natural gas as a promising alternative to petroleum-based fuels for mobile applications. ${ }^{23}$ The $\mathrm{CH}_{4}$ adsorption isotherms for MFM-130a have been measured at 298 and $273 \mathrm{~K}$ up to 20 bar using the same gravimetric method as for the $\mathrm{H}_{2}$ measurements (Figure S6). MFM-130a can adsorb a total of $6.9 \mathrm{mmol} / \mathrm{g}\left(154 \mathrm{~cm}^{3}(\mathrm{STP}) / \mathrm{g}\right)$ of $\mathrm{CH}_{4}$ at $298 \mathrm{~K}$ and $20 \mathrm{bar}$, which is moderate compared to other $\mathrm{Cu}$ (II)-based MOF materials with high $\mathrm{CH}_{4}$ capacities (Table 2) ${ }^{23}$ At $273 \mathrm{~K}$, the total $\mathrm{CH}_{4}$ adsorption capacity reaches $9.0 \mathrm{mmol} / \mathrm{g}\left(203 \mathrm{~cm}^{3}\right.$ $(\mathrm{STP}) / \mathrm{g}$ ) at 20 bar. High-pressure $\mathrm{CH}_{4}$ adsorption data up to $65 \mathrm{bar}$ at $298 \mathrm{~K}$ were also collected using a volumetric method and the results match well with the gravimetric measurements in the range of 0-20 bar (Figure 7). The excess $\mathrm{CH}_{4}$ uptake increases with pressure and then reaches a maximum value of $222 \mathrm{~cm}^{3}$ (STP) $/ \mathrm{g}$ (equivalent to $143 \mathrm{~cm}^{3}(\mathrm{STP}) / \mathrm{cm}^{3}$ ) at 47 bar. The total $\mathrm{CH}_{4}$ uptake, calculated using the crystal and skeletal densities of the material, reaches a value of $274 \mathrm{~cm}^{3}$
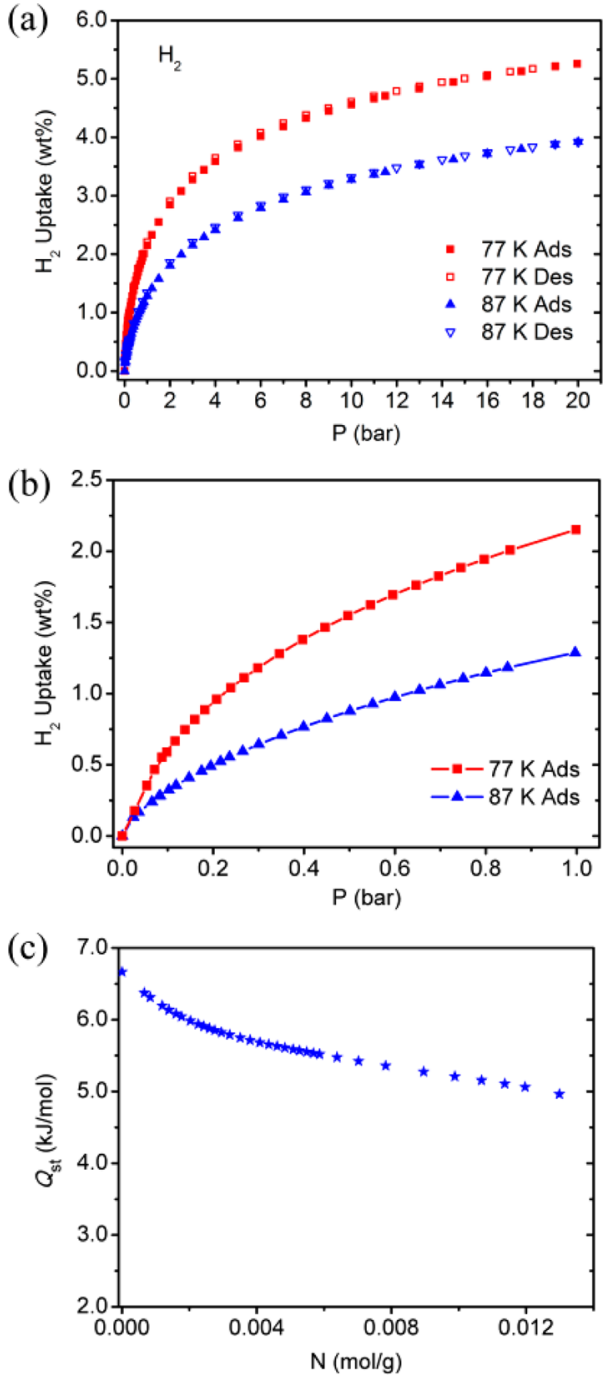

Figure 6. $\mathrm{H}_{2}$ isotherms for MFM-130a at 77 and $87 \mathrm{~K}$ (a) up to 20 bar and (b) up to 1 bar. (c) Isosteric heat of $\mathrm{H}_{2}$ adsorption as a function of loading for MFM-130a. "Ads" and "Des" represent adsorption and desorption, respectively.

(STP)/g at 65 bar, corresponding to volumetric uptake of 176 $\mathrm{cm}^{3}$ (STP) $/ \mathrm{cm}^{3}$. At 35 bar and $298 \mathrm{~K}$, although MFM-130a shows lower gravimetric $\mathrm{CH}_{4}$ uptake (excess: $219 \mathrm{~cm}^{3}$ (STP)/ g; total: $254 \mathrm{~cm}^{3}(\mathrm{STP}) / \mathrm{g}$ ) than highly porous MOFs such as NOTT-119 ${ }^{6 e}$ and NU-111, ${ }^{24}$ it exhibits higher volumetric $\mathrm{CH}_{4}$ capacity (excess: $141 \mathrm{~cm}^{3}$ (STP) $/ \mathrm{cm}^{3}$; total: $163 \mathrm{~cm}^{3}$ (STP)/ $\mathrm{cm}^{3}$, Table 2). The deliverable $\mathrm{CH}_{4}$ capacity is also an important factor when considering a material for practical onboard $\mathrm{CH}_{4}$ storage applications. The deliverable amount of $\mathrm{CH}_{4}$ in MFM-130a, defined as the difference in uptake between 65 and $5 \mathrm{bar}$, is $131 \mathrm{~cm}^{3} / \mathrm{cm}^{3}$. To gain further insight into the nature of framework $-\mathrm{CH}_{4}$ interactions, the isosteric heats of adsorption $\left(Q_{s t}\right)$ were calculated from isotherms collected at different temperatures. The $Q_{s t}$ for $\mathrm{CH}_{4}$ is $16.0 \mathrm{~kJ} / \mathrm{mol}$ at zero surface coverage and, importantly, remains almost constant with increased loading. At loadings higher than $5.0 \mathrm{mmol} / \mathrm{g}, Q_{\mathrm{st}}$ starts to increase slowly due to the $\mathrm{CH}_{4}-\mathrm{CH}_{4}$ interactions, which may play an important role at high loadings.

The $\mathrm{CO}_{2}$ and $\mathrm{N}_{2}$ adsorption isotherms for MFM-130a were also measured in the pressure range of $0-1$ bar at 298 and 273 $\mathrm{K}$ (Figure 8). The $\mathrm{CO}_{2}$ adsorption capacities for MFM-130a at 

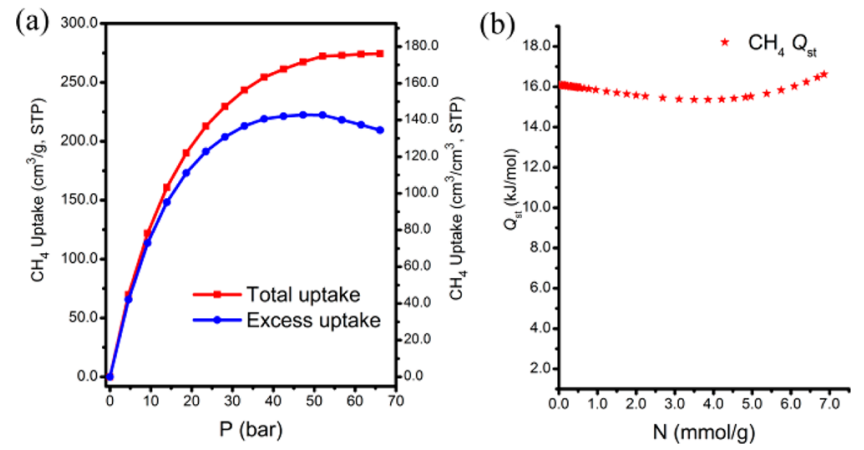

Figure 7. (a) $\mathrm{CH}_{4}$ sorption in MFM-130a in the pressure range of $0-$ 70 bar. (b) Variation of heat of adsorption for $\mathrm{CH}_{4}$ in MFM-130a as a function of loading.

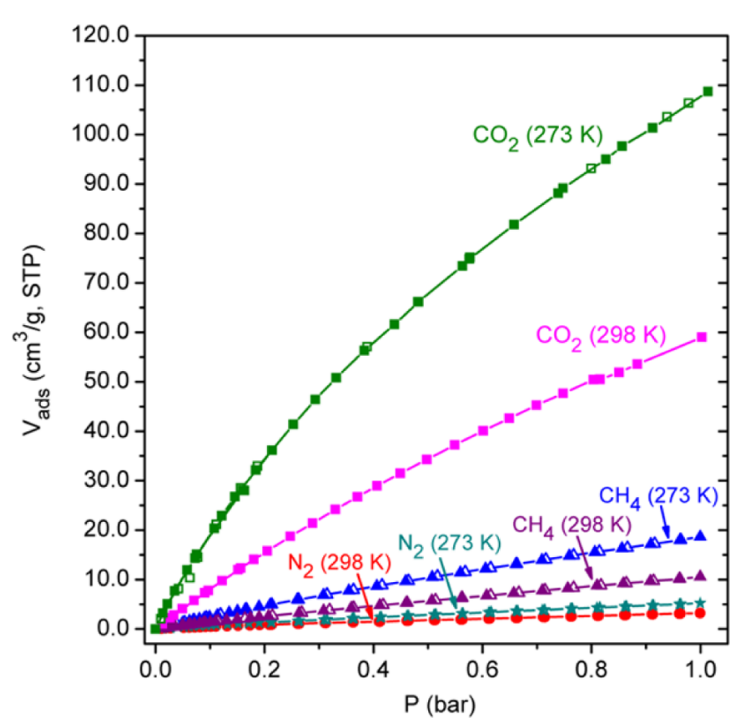

Figure 8. $\mathrm{CO}_{2}, \mathrm{CH}_{4}$, and $\mathrm{N}_{2}$ adsorption isotherms for MFM-130a at 298 and $273 \mathrm{~K}$ up to $1 \mathrm{bar}$.

$1 \mathrm{bar}$ are $109 \mathrm{~cm}^{3} / \mathrm{g}(21.3 \mathrm{wt} \%)$ and $59 \mathrm{~cm}^{3} / \mathrm{g}(11.6 \mathrm{wt} \%)$ at 273 and $298 \mathrm{~K}$, respectively. Although these values are lower than those for other highly porous $\mathrm{Cu}(\mathrm{II})$-based MOF materials such as NOTT-122 ${ }^{6 \mathrm{f}}(39.7 \mathrm{wt} \%$ at $273 \mathrm{~K}$; $20.4 \mathrm{wt}$ $\%$ at $298 \mathrm{~K}$ ) and NOTT-125 ${ }^{25}$ (40.0 wt\% at $273 \mathrm{~K} ; 18.2 \mathrm{wt} \%$ at $298 \mathrm{~K})$, which is attributed to the smaller pore size and the absence of $\mathrm{CO}_{2}$-favorable organic functionalities in MFM-130a, they are higher than for most other frameworks without open metal sites such as ZIFs under the same conditions. ${ }^{26}$ The heats of adsorption for $\mathrm{CO}_{2}$ were calculated based on the isotherms at different temperatures by using the virial method. MFM130a shows a high heat of $\mathrm{CO}_{2}$ adsorption of $26 \mathrm{~kJ} / \mathrm{mol}$ at zero surface coverage, reflecting a strong framework- $\mathrm{CO}_{2}$ interaction due to the synergistic effects from the narrowed pores caused by the presence of methyl groups and open $\mathrm{Cu}$ (II) sites. Compared to the $\mathrm{CO}_{2}$ adsorption, MFM-130a shows limited $\mathrm{N}_{2}$ and $\mathrm{CH}_{4}$ uptakes at 1 bar and room temperature. The $\mathrm{CO}_{2} /$ $\mathrm{N}_{2}$ adsorption selectivity values for MFM-130a are 29.2:1 at $298 \mathrm{~K}$ and $38.2: 1$ at $273 \mathrm{~K}$, as determined by evaluating the ratios of Henry's law constants from single-component isotherms. The $\mathrm{CO}_{2} / \mathrm{N}_{2}$ selectivity for MFM-130a is significantly higher than those for NOTT-122a (14.3:1) and NOTT-125a $(16: 1)$ at $298 \mathrm{~K}$. This increase in the selective adsorption of $\mathrm{CO}_{2}$ is because the methyl groups from the paraxylene units in MFM-130a reduce the accessible pore 
volume, thus creating enhanced overlapping potential for $\mathrm{CO}_{2}$ molecules, but at the same time, lowering the adsorption of $\mathrm{N}_{2}$. Also, MFM-130a shows respectable $\mathrm{CO}_{2} / \mathrm{CH}_{4}$ selectivities of 9.4 at $273 \mathrm{~K}$ and 7.1 at $298 \mathrm{~K}$.

Hydrocarbon Adsorption and Selectivities in MFM130a. Light hydrocarbons $\left(C_{1}-C_{3}\right)$ are important raw chemicals for various industrial applications, and the separation of the pure components from mixtures involves energyintensive cryogenic distillation processes. ${ }^{27}$ In particular, separation of $\mathrm{C}_{2}$ hydrocarbons from $\mathrm{CH}_{4}$ is an important industrial process for purification of $\mathrm{CH}_{4}$, and adsorptive separation has been shown to be an efficient and energyeconomic approach to these separation tasks. ${ }^{28}$ Several MOFs have been realized for their potential excellent selectivities of $\mathrm{C}_{2}$ hydrocarbons over $\mathrm{CH}_{4}$ due to the fine control of pore size/ shape and the presence of strong $\mathrm{C}_{2}$ hydrocarbon binding sites in the MOF structures. ${ }^{29}$ Although MOFs with pore sizes comparable to the kinetic diameters (3.3-4.4 $\AA$ ) of $\mathrm{C}_{2}$ hydrocarbons show enhanced $C_{2} / C_{1}$ selectivities, ${ }^{29 b, c}$ they typically suffer from low separation capacities. Therefore, the ideal MOFs for such separations should be ones showing optimized pore sizes and moderately high porosity, and at the same time, high affinities to $\mathrm{C}_{2}$ hydrocarbons. Accordingly, pure-component $\mathrm{C}_{2} \mathrm{H}_{2}, \mathrm{C}_{2} \mathrm{H}_{4}$ and $\mathrm{C}_{2} \mathrm{H}_{6}$ isotherms for MFM130a were collected at ambient temperatures (Figure 9). MFM130a shows moderately high $\mathrm{C}_{2} \mathrm{H}_{2}$ uptakes of $144 \mathrm{~cm}^{3}$ (STP)/ $\mathrm{g}$ at $273 \mathrm{~K}$ and $85.9 \mathrm{~cm}^{3} / \mathrm{g}$ at $298 \mathrm{~K}$ and 1 bar. The $\mathrm{C}_{2} \mathrm{H}_{2}$ capacities of MFM-130a are comparable to those of other MOFs with open metal sites showing high $\mathrm{C}_{2} \mathrm{H}_{2}$ uptakes under the same conditions (Table 3). MFM-130a also adsorbs high
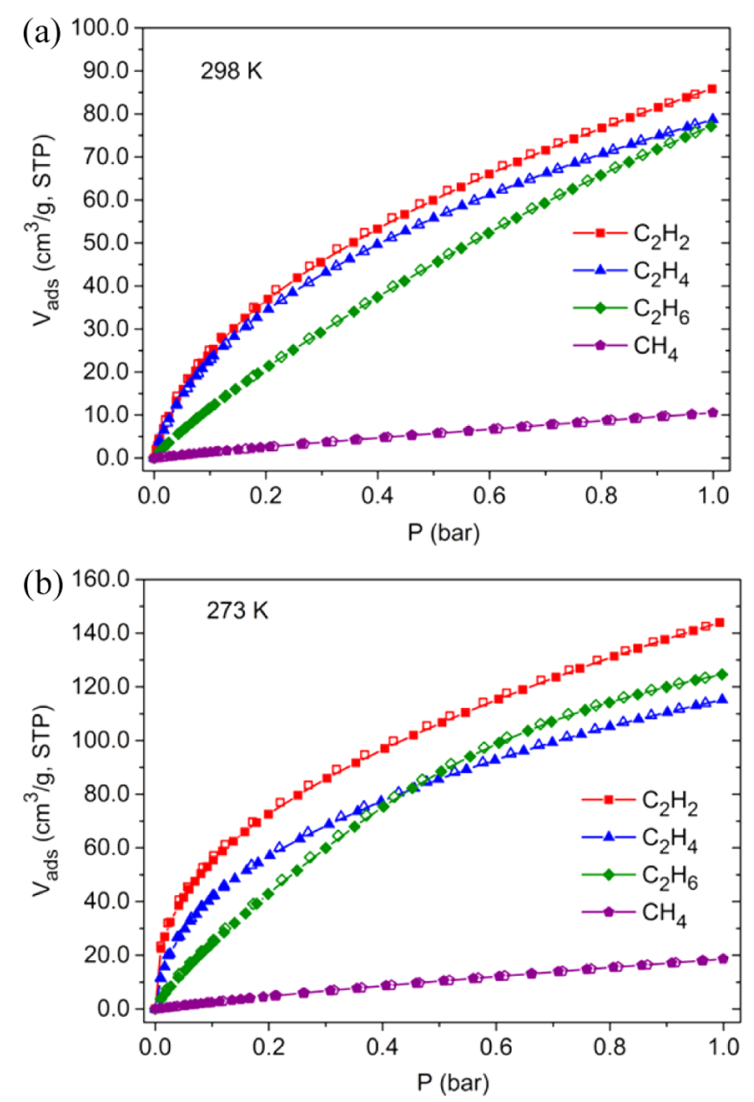

Figure 9. Adsorption isotherms for hydrocarbons in MFM-130a at (a) 298 and (b) $273 \mathrm{~K}$ in the pressure range of $0-1$ bar. amounts of $\mathrm{C}_{2} \mathrm{H}_{4}\left(115.2 \mathrm{~cm}^{3} / \mathrm{g}\right.$ at $273 \mathrm{~K} ; 78.7 \mathrm{~cm}^{3} / \mathrm{g}$ at $\left.298 \mathrm{~K}\right)$ and $\mathrm{C}_{2} \mathrm{H}_{6}\left(124.6 \mathrm{~cm}^{3} / \mathrm{g}\right.$ at $273 \mathrm{~K} ; 77.1 \mathrm{~cm}^{3} / \mathrm{g}$ at $\left.298 \mathrm{~K}\right)$ at 1 bar. Compared to $\mathrm{C}_{2} \mathrm{H}_{2}, \mathrm{C}_{2} \mathrm{H}_{4}$, and $\mathrm{C}_{2} \mathrm{H}_{6}$, MFM-130a shows considerably low $\mathrm{CH}_{4}$ uptake $\left(18.6 \mathrm{~cm}^{3} / \mathrm{g}\right.$ at $273 \mathrm{~K} ; 10.6 \mathrm{~cm}^{3} / \mathrm{g}$ at $298 \mathrm{~K}$ ) at $1 \mathrm{bar}$, indicating its potential for efficient separation of $\mathrm{C}_{2}$ hydrocarbons from $\mathrm{CH}_{4}$.

Virial analyses on the temperature-dependent hydrocarbons adsorption isotherms were performed to evaluate the binding interactions of $\mathrm{C}_{2}$ hydrocarbons with the framework of MFM130a and the separation selectivities (Table S2). The isosteric heats of adsorption at zero coverage, calculated based on the virial parameters, are 33.1, 34.0, and $25.0 \mathrm{~kJ} / \mathrm{mol}$ for $\mathrm{C}_{2} \mathrm{H}_{2}$, $\mathrm{C}_{2} \mathrm{H}_{4}$, and $\mathrm{C}_{2} \mathrm{H}_{6}$, respectively (i.e., $16 \mathrm{~kJ} / \mathrm{mol}$ for $\mathrm{CH}_{4}$ ). It is worth noting that the $\mathrm{C}_{2} \mathrm{H}_{2}$ adsorption enthalpy for MFM130a at low loading is higher than those for other $\mathrm{Cu}$ (II)-based MOFs such as MOF-505 $(25.4 \mathrm{~kJ} / \mathrm{mol})$ and $\mathrm{Cu}_{3}(\mathrm{BTC})_{2}(30.4$ $\mathrm{kJ} / \mathrm{mol}){ }^{31 \mathrm{a}}$ indicating that the open $\mathrm{Cu}(\mathrm{II})$ sites, coupled with the optimized pore diameter induced by the functionalization of methyl groups in MFM-130a, play an important role in enhancing the binding energy between $\mathrm{C}_{2} \mathrm{H}_{2}$ and the framework. The selectivities for $\mathrm{C}_{2}$ hydrocarbons $/ \mathrm{CH}_{4}$ were derived using Henry's law constants for individual hydrocarbons, based on the equation $S_{i j}=K_{\mathrm{H}}(i) / K_{\mathrm{H}}\left(\mathrm{CH}_{4}\right)$. MFM130a reveals moderate selectivities for $\mathrm{C}_{2} \mathrm{H}_{6}$ vs $\mathrm{CH}_{4}$ of 14.4 at $273 \mathrm{~K}$ and 10.1 at $298 \mathrm{~K}$. This is consistent with the fact that the interactions of saturated $\mathrm{C}_{2} \mathrm{H}_{6}$ with the framework is solely based on van der Waals interactions and the selective adsorption of $\mathrm{C}_{2} \mathrm{H}_{6}$ over $\mathrm{CH}_{4}$ is mainly based on the size effect of the adsorbates. Importantly, MFM-130a shows high selectivities for $\mathrm{C}_{2} \mathrm{H}_{2} / \mathrm{C}_{2} \mathrm{H}_{4}$ over $\mathrm{CH}_{4}$ of $66.5 / 60.0$ at $273 \mathrm{~K}$ and $34.7 / 30.3$ at $298 \mathrm{~K}$, respectively. Thus, MFM-130a represents a rare example of a framework material showing simultaneously high $\mathrm{C}_{2}$ hydrocarbons adsorption capacities and high $\mathrm{C}_{2}$ hydrocarbons $/ \mathrm{CH}_{4}$ selectivities at ambient temperature.

\section{CONCLUSIONS}

In summary, we have successfully synthesized in a novel and efficient manner two linear tetracarboxylate linkers containing paraxylene units and the respective $\left[\mathrm{Cu}_{2}(\mathrm{COO})_{4}\right]$-based foftype networks MFM-130 and MFM-131. Both these frameworks are non-interpenetrating, despite the extra-long organic linkers used, and comprise Kagomé lattice layers pillared by the organic oligoparaxylene backbones. In these structures, the paraxylene moieties adjacent to the isothphalate units significantly reduce the accessible openings of windows in the Kagomé lattice layers, thus effectively preventing interpenetration by two networks. This study provides a novel and efficient way for generating non-interpenetrating structures by using paraxylene units as building blocks for organic struts. The mechanical properties calculated for these two MOFs revealed that MFM-131 shows lower average Young's and shear moduli than MFM-130, explaining its instability upon desolvation. This approach gives further understanding of the mechanochemical properties in MOFs, especially those with large pore structures containing large organic units. The desolvated framework MFM-130a, densely decorated with methyl groups, shows moderately high porosity with BET surface area of $2173 \mathrm{~m}^{2} / \mathrm{g}$ and pore volume of $1.0 \mathrm{~cm}^{3} / \mathrm{g}$, with high $\mathrm{H}_{2}$ uptake capacities at both low and high pressures $(2.2 \mathrm{wt} \%$ at $1 \mathrm{bar} ; 5.3 \mathrm{wt} \%$ at 20 bar), albeit at low temperature $(77 \mathrm{~K})$. The observed increased isosteric heat of adsorption for $\mathrm{H}_{2}$ in MFM-130a compared to those of its structural analogues NOTT-102a, NOTT-110a, 
Table 3. Adsorption of $\mathrm{C}_{2} \mathrm{H}_{2}, \mathrm{C}_{2} \mathrm{H}_{4}$, and $\mathrm{C}_{2} \mathrm{H}_{6}$ in Various MOFs at $298 \mathrm{~K}$ and $1 \mathrm{bar}$

\begin{tabular}{|c|c|c|c|c|c|c|c|}
\hline material & $\begin{array}{l}\text { BET surface } \\
\text { area }\left(\mathrm{m}^{2} / \mathrm{g}\right)\end{array}$ & $\begin{array}{l}\text { pore volume } \\
\qquad\left(\mathrm{cm}^{3} / \mathrm{g}\right)\end{array}$ & $\begin{array}{c}D_{\mathrm{c}}^{b} \\
\left(\mathrm{~g} / \mathrm{cm}^{3}\right)\end{array}$ & $\begin{array}{c}\mathrm{C}_{2} \mathrm{H}_{2} \text { uptake } \\
\left(\mathrm{cm}^{3}(\mathrm{STP}) / \mathrm{g}\right)\end{array}$ & $\begin{array}{c}Q_{s t} \text { for } \mathrm{C}_{2} \mathrm{H}_{2} \\
(\mathrm{~kJ} / \mathrm{mol})\end{array}$ & $\begin{array}{c}\mathrm{C}_{2} \mathrm{H}_{4} \text { uptake } \\
\left(\mathrm{cm}^{3}(\mathrm{STP}) / \mathrm{g}\right)\end{array}$ & $\begin{array}{c}\mathrm{C}_{2} \mathrm{H}_{6} \text { uptake } \\
\left(\mathrm{cm}^{3}(\mathrm{STP}) / \mathrm{g}\right)\end{array}$ \\
\hline MFM-130a & 2173 & 1.0 & 0.642 & 85.9 & 33.1 & 78.7 & 77.1 \\
\hline $\mathrm{Cu}_{\mathbf{2}}(\mathbf{p z d c})_{2}(\mathbf{p y z})^{c, 30}$ & 571 & & 1.745 & 42 & 42.5 & & \\
\hline HKUST-1 ${ }^{31 \mathrm{a}}$ & 1401 & 0.76 & 0.879 & 201 & 30.4 & $165.9^{d}$ & $137.7^{d}$ \\
\hline MOF-505 ${ }^{31 a}$ & 1139 & 0.68 & 0.927 & 148 & 25.4 & $113.4^{d}$ & $123.1^{d}$ \\
\hline NOTT-102a $a^{31 b}$ & 3342 & 1.28 & 0.587 & 146 & & 128.2 & 125.9 \\
\hline ZIF-8 $8^{31 a}$ & 1112 & & 0.924 & 25 & 13.3 & $26.7^{e}$ & $44.2^{e}$ \\
\hline ZnMOF-74 ${ }^{32}$ & 747 & & 1.231 & 122 & 24.0 & & \\
\hline
\end{tabular}

${ }^{a}$ The pore volume values were calculated from $\mathrm{N}_{2}$ isotherms at $77 \mathrm{~K} .{ }^{b}$ Crystal density calculated from the single-crystal structure for the activated sample. ${ }^{c}$ pzdc $=$ pyrazine-2,3-dicarboxylate, pyz $=$ pyrazine. ${ }^{d}$ These data were taken from ref $31 \mathrm{~b} .{ }^{e}$ Measured at $301 \mathrm{~K} .{ }^{33}$

and NOTT-111a clearly indicates that the methyl functionality can enhance the $\mathrm{H}_{2}$-framework interactions. MFM-130a also shows high volumetric $\mathrm{CH}_{4}$ adsorption (total $163 \mathrm{~cm}^{3}$ (STP)/ $\mathrm{cm}^{3}$ at $\left.35 \mathrm{bar}\right)$ and deliverable $\left(131 \mathrm{~cm}^{3} / \mathrm{cm}^{3}\right.$ from 65 to $5 \mathrm{bar}$ ) capacities at room temperature. Furthermore, the high $\mathrm{CO}_{2}$ vs $\mathrm{N}_{2}, \mathrm{C}_{2} \mathrm{H}_{2}$ vs $\mathrm{CH}_{4}$, and $\mathrm{C}_{2} \mathrm{H}_{4}$ vs $\mathrm{CH}_{4}$ selectivities revealed by MFM-130a suggest it to be a promising material for potential carbon capture and natural gas purification applications.

\section{ASSOCIATED CONTENT}

\section{S Supporting Information}

The Supporting Information is available free of charge on the ACS Publications website at DOI: 10.1021/jacs.5b12312.

TGA, PXRD analyses, gas adsorption isotherms and virial fitting parameters, and theoretical calculations, including Figures S1-S8 and Tables S1 and S2 (PDF)

Crystallographic data for MFM-130 and MFM-131 (CIF)

\section{AUTHOR INFORMATION}

\section{Corresponding Authors}

*m.schroder@manchester.ac.uk

*stoddart@northwestern.edu

\section{Author Contributions}

${ }^{\times}$Y.Y. and M.J. contributed equally to this work.

\section{Notes}

The authors declare no competing financial interest.

\section{ACKNOWLEDGMENTS}

We thank the EPSRC (U.K. Sustainable Hydrogen Energy Consortium) and the University of Nottingham for funding. We are grateful to the EPSRC-funded National Crystallography Service at the University of Southampton, and Diamond Light Source for data collection on Beamline I19. M.S. gratefully acknowledges receipt of an ERC Advanced Grant and an EPSRC Programme Grant. This research is part (Project no. 94-938) of the Joint Center of Excellence in Integrated NanoSystems (JCIN) at King Abdul-Aziz City for Science and Technology (KACST) and Northwestern University (NU). The authors thank both KACST and NU for their continued support of this research. M.J. gratefully acknowledges The Netherlands Organization for Scientific Research (NWO) and the Marie Curie Cofund Action (Rubicon Fellowship). S.G. acknowledges the Swiss National Science Foundation for financial support. F.-X.C. acknowledges access to HPC resources from GENCI-IDRIS (grants x2015087069 and x2016087069).

\section{REFERENCES}

(1) (a) Lin, X.; Jia, J.; Hubberstey, P.; Schröder, M.; Champness, N. R. CrystEngComm 2007, 9, 438-448. (b) Dincă, M.; Long, J. R. Angew. Chem., Int. Ed. 2008, 47, 6766-6779. (c) Murray, L. J.; Dincă, M.; Long, J. R. Chem. Soc. Rev. 2009, 38, 1294-1314. (d) Lin, X.; Champness, N. R.; Schröder, M. Top. Curr. Chem. 2009, 293, 35-76. (e) Suh, M. P.; Park, H. J.; Prasad, T. K.; Lim, D.-W. Chem. Rev. 2012, 112, 782-835. (f) Sumida, K.; Rogow, D. L.; Mason, J. A.; McDonald, T. M.; Bloch, E. D.; Herm, Z. R.; Bae, T.-H.; Long, J. R. Chem. Rev. 2012, 112, 724-781. (g) He, Y.; Zhou, W.; Qian, G.; Chen, B. Chem. Soc. Rev. 2014, 43, 5657-5678.

(2) (a) Zhao, D.; Timmons, D. J.; Yuan, D.; Zhou, H.-C. Acc. Chem. Res. 2011, 44, 123-133. (b) Lu, W.; Wei, Z.; Gu, Z.-Y.; Liu, T.-F.; Park, J.; Park, J.; Tian, J.; Zhang, M.; Zhang, Q.; Gentle, T., III; Bosch, M.; Zhou, H.-C. Chem. Soc. Rev. 2014, 43, 5561-5593.

(3) (a) Lin, X.; Jia, J.; Zhao, X. B.; Thomas, K. M.; Blake, A. J.; Champness, N. R.; Hubberstey, P.; Schröder, M. Angew. Chem., Int. Ed. 2006, 45, 7358-7364. (b) Lin, X.; Telepeni, I.; Blake, A. J.; Dailly, A.; Brown, C. M.; Simmons, J. M.; Zoppi, M.; Walker, G. S.; Thomas, K. T.; Mays, T. J.; Hubberstey, P.; Champness, N. R.; Schröder, M. J. Am. Chem. Soc. 2009, 131, 2159-2171. (c) Yang, S.; Lin, X.; Dailly, A.; Blake, A. J.; Champness, N. R.; Hubberstey, P.; Schröder, M. Chem. Eur. J. 2009, 15, 4829-4835. (d) Li, B.; Wen, H.-M.; Wang, H.; Wu, H.; Tyagi, M.; Yildirim, T.; Zhou, W.; Chen, B. J. Am. Chem. Soc. 2014, 136, 6207-6210. (e) Kennedy, R. D.; Krungleviciute, V.; Clingerman, D. J.; Mondloch, J. E.; Peng, Y.; Wilmer, C. E.; Sarjeant, A. A.; Snurr, R. Q.; Hupp, J. T.; Yildirim, T.; Farha, O. K.; Mirkin, C. A. Chem. Mater. 2013, 25, 3539-3543. (f) Wang, X.-S.; Ma, S.; Rauch, K.; Simmons, J. M.; Yuan, D.; Wang, X.; Yildirim, T.; Cole, W. C.; López, J. J.; de Meijere, A.; Zhou, H.-C. Chem. Mater. 2008, 20, 3145-3152.

(4) O'Keeffe, M.; Yaghi, O. M. Chem. Rev. 2012, 112, 675-702.

(5) (a) Furukawa, H.; Ko, N.; Go, Y. B.; Aratani, N.; Choi, S. B.; Choi, E.; Yazaydin, A. O.; Snurr, R. Q.; O’Keeffe, M.; Kim, J.; Yaghi, O. M. Science 2010, 329, 424-428. (b) Farha, O. K.; Eryazici, I.; Jeong, N. C.; Hauser, B. G.; Wilmer, C. E.; Sarjeant, A. A.; Snurr, R. Q.; Nguyen, S. B. T.; Yazaydin, A. Ö.; Hupp, J. T. J. Am. Chem. Soc. 2012, 134, 15016-15021.

(6) (a) Nouar, F.; Eubank, J. F.; Bousquet, T.; Wojtas, L.; Zaworotko, M. J.; Eddaoudi, M. J. Am. Chem. Soc. 2008, 130, 1833-1835. (b) Yan, Y.; Lin, X.; Yang, S.; Blake, A. J.; Dailly, A.; Champness, N. R; Hubberstey, P.; Schröder, M. Chem. Commun. 2009, 1025-1027. (c) Yan, Y.; Telepeni, I.; Yang, S.; Lin, X.; Kockelmann, W.; Dailly, A.; Blake, A. J.; Lewis, W.; Walker, G. S.; Allan, D. R.; Barnett, S. A.; Champness, N. R.; Schröder, M. J. Am. Chem. Soc. 2010, 132, 40924094. (d) Yan, Y.; Blake, A. J.; Lewis, W.; Barnett, S. A.; Dailly, A.; Champness, N. R.; Schröder, M. Chem. - Eur. J. 2011, 17, 1116211170. (e) Yan, Y.; Yang, S.; Blake, A. J.; Lewis, W.; Poirier, E.; Barnett, S. A.; Champness, N. R.; Schröder, M. Chem. Commun. 2011, 47, 9995-9997. (f) Yan, Y.; Suyetin, M.; Bichoutskaia, E.; Blake, A. J.; Allan, D. R.; Barnett, S. A.; Schröder, M. Chem. Sci. 2013, 4, 17311736.

(7) (a) Zhang, M.; Chen, Y.-P.; Bosch, M.; Gentle, T., III; Wang, K.; Feng, D.; Wang, Z. U.; Zhou, H.-C. Angew. Chem., Int. Ed. 2014, 53, 
815-818. (b) Dincă, M.; Dailly, A.; Long, J. R. Chem. - Eur. J. 2008, 14, 10280-10285.

(8) (a) Ma, S.; Sun, D.; Ambrogio, M.; Fillinger, J. A.; Parkin, S.; Zhou, H.-C. J. Am. Chem. Soc. 2007, 129, 1858-1859. (b) Furukawa, H.; Go, Y. B.; Ko, N.; Park, Y. K.; Uribe-Romo, F. J.; Kim, J.; O’Keeffe, M.; Yaghi, O. M. Inorg. Chem. 2011, 50, 9147-9152.

(9) (a) Oisaki, K.; Li, Q.; Furukawa, H.; Czaja, A. U.; Yaghi, O. M. J. Am. Chem. Soc. 2010, 132, 9262-9264. (b) Farha, O. K.; Malliakas, C. D.; Kanatzidis, M. G.; Hupp, J. T. J. Am. Chem. Soc. 2010, 132, 950952.

(10) Grunder, S.; Valente, C.; Whalley, A. C.; Sampath, S.; Portmann, J.; Botros, Y. Y.; Stoddart, J. F. Chem. - Eur. J. 2012, 18, 15632-15649.

(11) Deng, H.; Grunder, S.; Cordova, K. E.; Valente, C.; Furukawa, H.; Hmadeh, M.; Gándara, F.; Whalley, A. C.; Liu, Z.; Asahina, S.; Kazumori, H.; O’Keeffe, M.; Terasaki, O.; Stoddart, J. F.; Yaghi, O. M. Science 2012, 336, 1018-1023.

(12) Lörtscher, E.; Elbing, M.; Tschudy, M.; von Hänisch, C.; Weber, H. B.; Mayor, M.; Riel, H. ChemPhysChem 2008, 9, 2252-2258.

(13) (a) Reid, C. R.; Thomas, K. M. Langmuir 1999, 15, 3206-3218. (b) Reid, C. R.; Thomas, K. M. J. Phys. Chem. B 2001, 105, 1061910629.

(14) (a) Sheldrick, G. M. SHELXL2013: Program for Refinement of Crystal Structures; University of Göttingen: Göttingen, Germany, 2013.

(b) Sheldrick, G. M. Acta Crystallogr., Sect. A: Found. Crystallogr. 2008, 64, 112-122.

(15) Spek, A. L. Acta Crystallogr., Sect. C 2015, 71, 9-18.

(16) (a) Ortiz, A. U.; Boutin, A.; Fuchs, A. H.; Coudert, F.-X. J. Chem. Phys. 2013, 138, 174703. (b) Ortiz, A. U.; Boutin, A.; Fuchs, A. H.; Coudert, F.-X. Phys. Rev. Lett. 2012, 109, 195502.

(17) Tan, J.-C.; Civalleri, B.; Lin, C.-C.; Valenzano, L.; Galvelis, R.; Chen, P.-F.; Bennett, T. D.; Mellot-Draznieks, C.; Zicovich-Wilson, C. M.; Cheetham, A. K. Phys. Rev. Lett. 2012, 108, 095502.

(18) Ogborn, J. M.; Collings, I. E.; Moggach, S. A.; Thompson, A. L.; Goodwin, A. L. Chem. Sci. 2012, 3, 3011-3017.

(19) Bouëssel du Bourg, L.; Ortiz, A. U.; Boutin, A.; Coudert, F.-X. APL Mater. 2014, 2, 124110.

(20) Yan, Y.; Yang, S.; Blake, A. J.; Schröder, M. Acc. Chem. Res. 2014, 47, 296-307.

(21) (a) Dincă, M.; Long, J. R. Angew. Chem., Int. Ed. 2008, 47, 6766-6779. (b) Peterson, V. K.; Liu, Y.; Brown, C. M.; Kepert, C. J. J. Am. Chem. Soc. 2006, 128, 15578-15579.

(22) Rowsell, J. L. C.; Millward, A. R.; Park, K. S.; Yaghi, O. M. J. Am. Chem. Soc. 2004, 126, 5666-5667.

(23) (a) Peng, Y.; Krungleviciute, V.; Eryazici, I.; Hupp, J. T.; Farha, O. K.; Yildirim, T. J. Am. Chem. Soc. 2013, 135, 11887-11894. (b) He, Y.; Zhou, W.; Yildirim, T.; Chen, B. Energy Environ. Sci. 2013, 6, $2735-2744$.

(24) Farha, O. K.; Wilmer, C. E.; Eryazici, I.; Hauser, B. G.; Parilla, P. A.; O’Neill, K.; Sarjeant, A. A.; Nguyen, S. B. T.; Snurr, R. Q.; Hupp, J. T. J. Am. Chem. Soc. 2012, 134, 9860-9863.

(25) Alsmail, N. H.; Suyetin, M.; Yan, Y.; Cabot, R.; Krap, C. P.; Lü, J.; Easun, T. L.; Bichoutskaia, E.; Lewis, W.; Blake, A. J.; Schröder, M. Chem. - Eur. J. 2014, 20, 7317-7324.

(26) (a) Banerjee, R.; Furukawa, H.; Britt, D.; Knobler, C.; O’Keefe, M.; Yaghi, O. M. J. Am. Chem. Soc. 2009, 131, 3875-3877. (b) Morris, W.; Leung, B.; Furukawa, H.; Yaghi, O. K.; He, N.; Hayashi, H.; Houndonougbo, Y.; Asta, M.; Laird, B. B.; Yaghi, O. M. J. Am. Chem. Soc. 2010, 132, 11006-11008.

(27) Eldridge, R. B. Ind. Eng. Chem. Res. 1993, 32, 2208-2212.

(28) (a) Wu, H.; Gong, Q.; Olson, D. H.; Li, J. Chem. Rev. 2012, 112, 836-868. (b) He, Y.; Zhou, W.; Krishna, R.; Chen, B. Chem. Commun. 2012, 48, 11813-11831.

(29) (a) Bloch, E. D.; Queen, W. L.; Krishna, R.; Zadrozny, J. M.; Brown, C. M.; Long, J. R. Science 2012, 335, 1606-1610. (b) Herm, Z. R.; Bloch, E. D.; Long, J. R. Chem. Mater. 2014, 26, 323-338. (c) Das, M. C.; Xu, H.; Xiang, S.; Zhang, Z.; Arman, H. D.; Qian, G.; Chen, B. Chem. - Eur. J. 2011, 17, 7817-7822. (d) Xiang, S. C.; Zhang, Z. J.; Zhao, C. G.; Hong, K.; Zhao, X. B.; Ding, D. R.; Xie, M. H.; Wu, C.
D.; Das, M. C.; Gill, R.; Thomas, K. M.; Chen, B. Nat. Commun. 2011 , 2, 204-209.

(30) Matsuda, R.; Kitaura, R.; Kitagawa, S.; Kubota, Y.; Belosludov, R. V.; Kobayashi, T. C.; Sakamoto, H.; Chiba, T.; Takata, M.; Kawazoe, Y.; Mita, Y. Nature 2005, 436, 238-241.

(31) (a) Xiang, S.; Zhou, W.; Gallegos, J. M.; Liu, Y.; Chen, B. J. Am. Chem. Soc. 2009, 131, 12415-12419. (b) He, Y.; Krishna, R.; Chen, B. Energy Environ. Sci. 2012, 5, 9107-9120.

(32) Xiang, S.; Zhou, W.; Zhang, Z.; Green, M. A.; Liu, Y.; Chen, B. Angew. Chem., Int. Ed. 2010, 49, 4615-4618.

(33) He, Y.; Zhang, Z.; Xiang, S.; Wu, H.; Fronczek, F. R.; Zhou, W.; Krishna, R.; O'Keeffe, M.; Chen, B. Chem. - Eur. J. 2012, 18, 19011904. 